JOURNAL OF MOLECULAR LIOUIDS (GERMANY)

Accepted February $11^{\text {th }} 2017$

ISSN: 0167-7322

Impact Factor: 2.740

PUBLISHER: ELSEVIER

\title{
NUMERICAL STUDY OF HEAT SOURCE/SINK EFFECTS ON DISSIPATIVE MAGNETIC NANOFLUID FLOW FROM A NON-LINEAR INCLINED STRETCHING/SHRINKING SHEET
}

\author{
Thirupathi Thumma ${ }^{*}$, O. Anwar Bég ${ }^{2}$ and A. Kadir ${ }^{3}$ \\ ${ }^{1}$ Department of Mathematics, B V Raju Institute of Technology, Narsapur, Medak 502313, \\ Telangana., India. \\ ${ }^{2}$ Fluid Mechanics, Propulsion and Nanosystems, Aeronautical and Mechanical Engineering, \\ Newton Bldg., University of Salford, Manchester, M54WT, UK. \\ ${ }^{3}$ Materials and Corrosion, Petroleum and Gas Engineering, Newton Bldg., University of \\ Salford, Manchester, M54WT, UK. \\ *Corresponding Author: thirupathi.thumma@gmail.com
}

\begin{abstract}
This paper numerically investigates radiative magnetohydrodynamic mixed convection boundary layer flow of nanofluids over a nonlinear inclined stretching/shrinking sheet in the presence of heat source/sink and viscous dissipation. The Rosseland approximation is adopted for thermal radiation effects and the Maxwell-Garnetts and Brinkman models are used for the effective thermal conductivity and dynamic viscosity of the nanofluids respectively. The governing coupled nonlinear momentum and thermal boundary layer equations are rendered into a system of ordinary differential equations via local similarity transformations with appropriate boundary conditions. The non-dimensional, nonlinear, well-posed boundary value problem is then solved with the Keller box implicit finite difference scheme. The emerging thermo-physical dimensionless parameters governing the flow are the magnetic field parameter, volume fraction parameter, power-law stretching parameter, Richardson number, suction/injection parameter, Eckert number and heat source/sink parameter. A detailed study of the influence of these parameters on velocity and temperature distributions is conducted. Additionally the evolution of skin friction coefficient and Nusselt number values with selected parameters is presented. Verification of numerical solutions is achieved via benchmarking with some limiting cases documented in previously reported results, and generally very good correlation is demonstrated. This investigation is relevant to fabrication of magnetic nanomaterials and high temperature treatment of magnetic nano-polymers.
\end{abstract}

Keywords: Keller-Box Method; Non-linear Stretching/Shrinking Sheet; Heat Source/Sink; Nanofluid; power-law stretching parameter; magnetic nanomaterials processing.

\section{INTRODUCTION}

Nanofluids constitute a subsection of molecular liquids designed to operate at the nanoscale. The rapid growth of nanotechnology has witnessed a significant interest in such 
fluids across the entire breadth of engineering, including aerospace, manufacturing, energy technologies and medical industries. It is well-known that the term nanofluid was introduced by Choi [1] in 1995, to describe a fluid comprising solid nanoparticles with size typically of 1to $100 \mathrm{~nm}$ suspended in a liquid. Common base fluids are water, ethylene glycol, oil and lubricants. Nanoparticles which include aluminium, copper, silver and titanium metals with/without their oxides are of great scientific interest as they are effectively a bridge between bulk materials and molecular structures. The thermal conductivity of the nanoparticles is high as compared to the conventional fluids, as verified in experimental studies conducted by Eastman et al. [2] and Xuan and Lin [3] shown that with a small volumetric fraction of nanoparticles (typically less than 5\%), the thermal conductivity of the base fluid is enhanced by 10-20\%. Recently Selimefendigil and Oztop [4] reported that $14.11 \%$ of averaged heat transfer enhancement is obtained when both cavities are filled with nanofluids at the highest value of nanoparticle volume fractions. Therefore, these nanofluids are capable of promoting energy efficiency, improving thermal conductivity and thermal properties of heat transport of base fluid. Nanofluids have therefore found significant applications in diverse areas including rocket fuels, cooling of nuclear reactors, manufacturing of nanopolymer sheets, bath cooling of a metallic plates and wires, glass fabrication etc. Recently many interesting studies have been reported by various researchers which includes Power law fluids in a cavity (Selimefendigil and Oztop [5]), Oldroyd-B fluids (Hayat et al. [6]), Maxwell fluids (Abbasi and Shehzad [7]), nanofluid filled in lid driven square enclosure with a rotating cylinder (Selimefendigil and Oztop [8]), Squeezing nanofluid flows (Hayat et al. [9]), Ferrofluid flow in a partially heated square enclosures (Selimefendigil and Oztop [10]) .In certain polymeric processing operations, materials are stretched or contracted at high temperature through slits under various thermal conditions to modify the properties. Mathematical modelling of such processes provides an important compliment to experimental laboratory investigations. Numerical analysis of viscous flow and heat transfer over a nonlinearly stretching sheet has been conducted for a Newtonian fluid by Cortell [11] with various thermal boundary conditions using a Runge-Kutta (RK) algorithm. Rana et al. [12] employed a finite element method to simulate two-dimensional non-Newtonian nanofluid stretching sheet flow from a slit with viscous heating and deformation effects. Furthermore numerous reviews on thermal enhancing properties of nanofluids have been addressed in [13$15]$.

Magnetohydrodynamic (MHD) viscous incompressible flow of electrically conducting fluid also features in an extensive range of technologies including magnetic materials processing, heat transfer control, purification of crude oil, Hall generators etc. In such flows a Lorentzian magnetic body force is generated transverse to the direction of the applied magnetic field which is instrumental in regulating high temperature plasmas, energy flux and also damping oscillations. Magnetic nanofluids are colloidal suspensions containing magnetizable nanoparticles which possess magnetic, fluid and thermal properties. Fourth order R-K method based shooting technique has been employed by Freidoonimehr et al. [16] to solve the differential equations describing the unsteady MHD free convection flow in a nanofluid past a permeable accelerating stretching vertical surface in the form of assisting flow. Makinde et al. [17] studied the combined effects of buoyancy force and convective heating on MHD stagnation point nanofluid flow from a vertically heated stretching/shrinking sheet as well as Makinde et al. [18] also studied MHD flow of variable viscosity nanofluid over radially stretching convective surface. Selimefendigil and Oztop [1921] adopted FEM to investigate the influence of inclined magnetic field under different geometries which includes backward facing step, cavity with oscillating lid and isothermal cylinders portioned with a conductive ring respectively. As well as influence of inclined 
magnetic field imposed to upper and lower triangular domains by Selimefendigil et al. [22]. Hayat et al. [23] used a homotopy method to analyze the three-dimensional hydromagnetic viscous flow of nanofluid subject to convective surface boundary conditions. Abolbashari et al. [24] employed HAM to study the entropy analysis in an unsteady magneto hydrodynamic nanofluid regime adjacent to an accelerating stretching permeable surface with the water as the base fluid. The analytical solution for two dimensional MHD mixed convection viscoelastic fluid flow over a porous wedge with thermal radiation is investigated by Rashidi et al. [25] by adopting HAM. Heat and Mass Transfer of a steady MHD convective and Slip flow due to a rotating disk with viscous dissipation and Ohmic heating reported by Rashidi and Erfani [26] by adopting DTM with Pade approximation. Very recently MHD nanofluid flow in stretching/shrinking convergent / divergent channel with Duan-Rach Approach (DRA) by Dogonchi and Ganji [27], buoyancy flow and heat transfer of MHD flow with KKL (Koo- Kleinstreuer -Li) effective thermal conductivity and viscosity correlation model by Dogonchi and Ganji [28].

As elaborated earlier, transport phenomena from a stretching/shrinking sheet have attracted many researchers owing to the relevance of this type of flow to materials processing operations including extrusion of polymer sheets, annealing of copper sheets in metallurgy etc. The pioneering work in this area was presented by Sakiadis [29-30]. Crane [31] extended the Sakiadis model to study the forced convection flow from a stretching sheet in a viscous incompressible fluid. Goldstein [32] elaborated that the shrinking flow is essentially a backward flow and the mass suction is needed to maintain the flow. It is worth mentioning here that the stretching sheet velocity formulation need not necessarily be a linear one. In polymeric extrusion processes nonlinear stretching is common. Gupta and Gupta [33] further verified that the stretching of the sheet is not necessarily linear for heat and mass transfer problems in the presence of suction/blowing. Motivated by emerging applications of nanopolymers, Hamad and Ferdows [34] reported similarity solutions for viscous flow and heat transfer of nanofluid over a non-linearly stretching sheet with an assumption that the stretching velocity and transverse magnetic field is varied as a power function of the distance from the origin. They observed that behavior of the fluid flow changes with the type of nanoparticles type and furthermore also considered stagnation point, porous medium, internal heat generation and suction effects. Nonlinearity in the stretching sheet process has been addressed with quadratic (power-law) and also exponential models. Akyildiz and Siginer [35] obtained Galerkin-Legendre spectral solutions for thermal boundary layer flow over a nonlinear stretching sheet with a power-law stretching model. Stagnation point flow over a permeable stretching/shrinking sheet in a copper-water nanofluid was investigated by Bachok et al. [36]. Steady state two-dimensional stagnation-point flow of a water based nanofluid over an exponentially stretching/shrinking sheet was investigated with a computational shooting method by Bachok et al. [37]. They observed that the similarity solution for the steady stagnation-point flow over an exponentially stretching/shrinking sheet is larger than compared with the linear stretching/shrinking sheet case solution. Rana and Bhargava [38] investigated laminar boundary layer fluid flow which results from the non-linear stretching of flat surface in a nanofluid with a finite element method.

Heat generation/ absorption effects arise in many thermo fluid processes including cooling of electronic equipment, hot spot/sink modification of polymer manufacture, cooling/heating of plastic products etc. Thermal radiation heat transfer also arises in high temperature materials synthesis. Selimefendigil and Oztop [39] reported that the elastic modulus of the side walls can be used to control the fluid flow and heat transfer inside the cavity and cylindrical nano particles gives the best performance in terms of heat transfer enhancement. Khan et al. [40] investigated non-aligned magnetized stagnation point flow of variable viscosity nanofluids 
from a stretching sheet with radiative heat flux effects. Very recently Selimefendigil and Oztop [41] reported that as the value of the elastic modulus of the inclined wall and nanoparticle volume fraction increase, local and average heat transfer enhances. Gorla and Gireesha [42] presented dual solutions for stagnation point flow and heat transfer of Williamson viscoelastic nanofluids from a stretching/shrinking sheet under convective boundary conditions, showing that thermal boundary layer thickness increases with Williamson parameter (viscoelastic effect). Khan et al. [43] studied three-dimensional flow of nanofluid over a non-linearly stretching sheet with radiative flux effects. Selimefendigil and Oztop [44] reported that the local and averaged heat transfer enhances as the value of the solid volume fraction of the nanoparticle increases and this more effective for higher values of Richardson number.

Although significant studies have been reported of magnetic, radiative and nanofluid flows from horizontal stretching/contracting sheets, relatively sparse attention has been afforded to inclined stretching/contracting sheet magnetized nanofluid flows in the presence of a heat source/sink. Therefore, the objective of present investigation is to extend the work reported by Hamad and Ferdows [34] and Pal et al. [45] by considering heat source/sink effects in addition to viscous dissipation for two different water based Newtonian nanofluids in transport from an inclined non-linear stretching/shrinking sheet. An implicit finite difference scheme due to Keller [46] has been adopted for solving the coupled non-linear ordinary differential equation system emerging. Extensive details of the mathematical formation of the problem, numerical method of solution, grid independence study and validation are presented. The effects of various governing physical parameters on velocity and temperature profiles are discussed via figures and tables in section 5. Finally, a summary of noteworthy results are presented in section 6. The current simulations are relevant to electromagnetic nanofluid materials processing under high temperature.

\section{MATHEMATICAL FORMULATION OF THE MODEL}

Consider the steady, two-dimensional, laminar, incompressible, magnetohydrodynamic dissipative flow of an electrically-conducting nanofluid from an inclined stretching or shrinking sheet, orientated at an angle, $\alpha\left(0^{\circ} \leq \alpha \leq 90^{\circ}\right)$ to the vertical. The physical model is illustrated in Fig. 1 


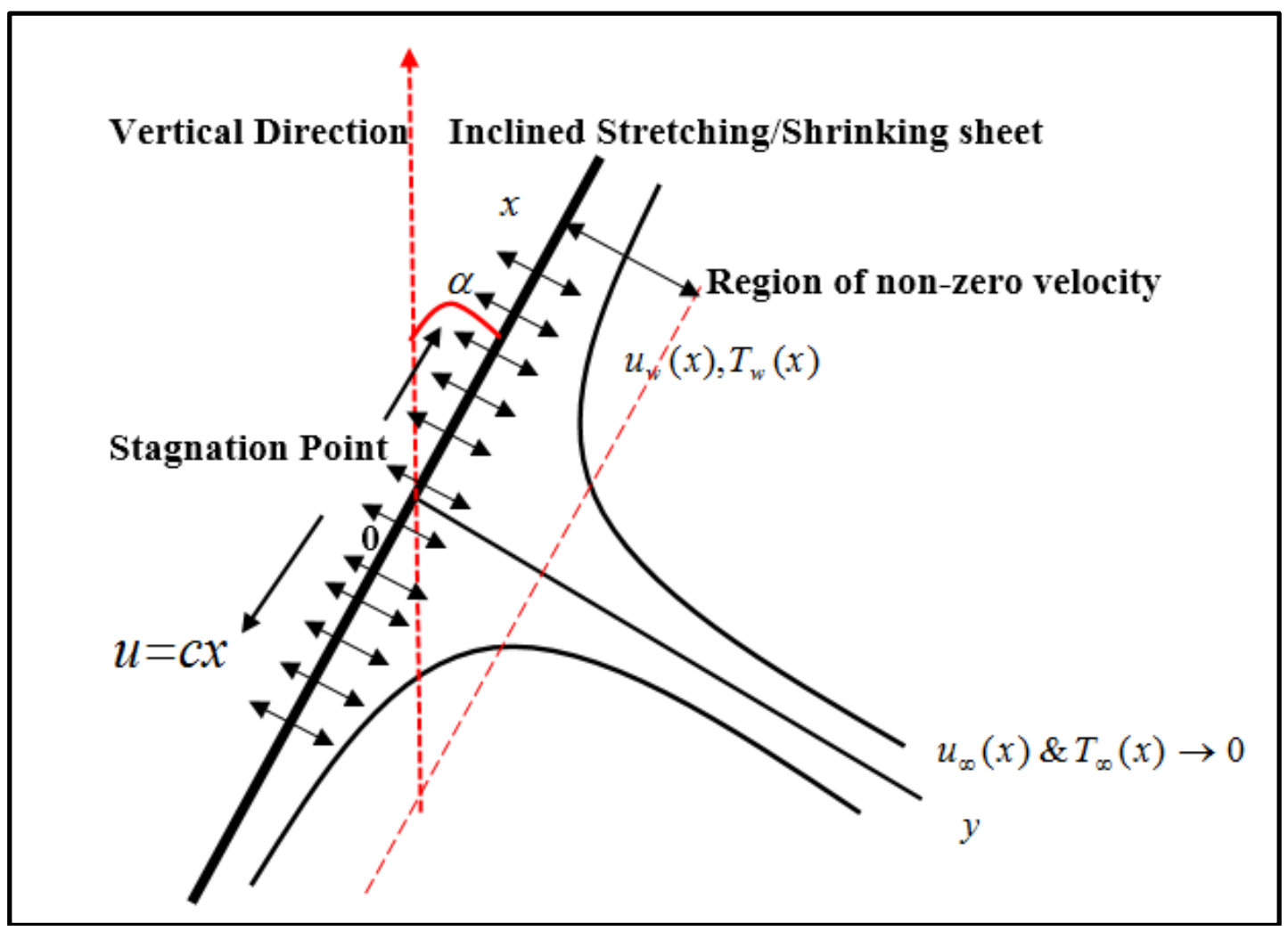

Fig. 1. Flow configuration and coordinate system

The stretching of the sheet, which physically represents a nano polymer, is induced by applying two equal and opposite forces simultaneously along the x-axis. By keeping the origin fixed, the sheet is stretched with nonlinear velocity $u_{w}(x)=c x^{n}$, where $\mathrm{c}$ is a constant and $\mathrm{n}$ is a nonlinear stretching parameter. The $\mathrm{x}$-axis is directed along the continuous stretching/shrinking sheet and the $\mathrm{y}$-axis is measured normal to the $\mathrm{x}$-axis. It is assumed that flow takes place for $y \geq 0$ and the temperature at the stretching/shrinking sheet takes a constant value $T_{w}>0$ while the temperature of the ambient nanofluid takes the constant value $T_{\infty}$ as $y \rightarrow \infty$. The inclination angles $0^{0}, 90^{\circ}$ and $0^{\circ}<\alpha<90^{\circ}$ represent the vertical, horizontal and general inclined stretching (or shrinking) sheet respectively. A non-uniform magnetic field of strength $B(x)=B_{o} x^{(m-1) / 2}$ is applied in the transverse direction, where $B_{o}$ is constant related to magnetic field and $m(\neq-1)$ is a power law exponent. Furthermore, the base fluid and the nanoparticles are in thermal equilibrium and no-slip occurs between them. Under these aforementioned assumptions the continuity, momentum and energy equations following [45], in the presence of thermal radiation, magnetic field, viscous dissipation and heat generation/absorption for the mixed convection flow can be shown to take the form:

Continuity equation

$\frac{\partial u}{\partial x}+\frac{\partial u}{\partial y}=0$

Momentum equation 
$u \frac{\partial u}{\partial x}+v \frac{\partial u}{\partial y}=\frac{\mu_{n f}}{\rho_{n f}} \frac{\partial^{2} u}{\partial y^{2}}+\frac{(\rho \beta)_{n f}}{\rho_{n f}} g\left(T-T_{\infty}\right) \cos (\alpha)-\frac{\sigma_{n f} B^{2}(x)}{\rho_{n f}} u$

Energy equation.

$u \frac{\partial T}{\partial x}+v \frac{\partial T}{\partial y}=\frac{\mu_{n f}}{\rho_{n f}} \frac{\partial^{2} T}{\partial y^{2}}+\frac{1}{\left(\rho c_{p}\right)_{n f}} \frac{\partial q_{r}}{\partial y}+\frac{\mu_{n f}}{\left(\rho c_{p}\right)_{n f}}\left(\frac{\partial u}{\partial y}\right)^{2}+\frac{Q_{0}}{\left(\rho c_{p}\right)_{n f}}\left(T_{w}-T_{\infty}\right)$

The following boundary conditions are imposed at the stretching/shrinking sheet and in the freestream:

$\begin{array}{ll}\text { at } y=0 ; & \left\{\begin{array}{l}u_{w}(x)= \pm c x^{n} \\ v=v_{w} \\ T=T_{w}(x)=T_{\infty}+b x^{n}\end{array}\right\} \\ \text { as } y \rightarrow \infty \quad\left\{\begin{array}{l}u \rightarrow 0 \\ T=T_{\infty}\end{array}\right.\end{array}$

Here $\mathrm{u}$ and $\mathrm{v}$ are the velocity components along the $\mathrm{x}$ - axis and $\mathrm{y}$-axis directions respectively and $\mathrm{c}$ is a constant for which $c>0$ corresponds to the stretching sheet and $c<0$ for the shrinking sheet, $\mathrm{T}$ is the temperature of the nanofluid, $\mathrm{g}$ is the acceleration due to gravity, $v_{w}$ is the wall mass flux with $v_{w}<0$ for suction and $v_{w}>0$ for injection respectively. Furthermore, $\mu_{n f}$ is the coefficient of dynamic viscosity of the nanofluid, $\beta_{n f}$ is the thermal expansion coefficient of the nanofluid, $\alpha_{n f}$ is the thermal diffusivity of the nanofluid, $\rho_{n f}$ is the effective density of the nanofluid, and $\left(\rho c_{p}\right)_{n f}$ is the heat capacitance of the nanofluid which are defined as follows:

$$
\begin{aligned}
& \alpha_{n f}=\frac{k_{n f}}{\left(\rho c_{p}\right)_{n f}}, \mu_{n f}=\frac{\mu_{f}}{(1-\phi)^{2.5}}, \rho_{n f}=(1-\phi) \rho_{f}+\phi \rho_{s},(\rho \beta)_{n f}=(1-\phi)(\rho \beta)_{f}+\phi(\rho \beta)_{s}, \\
& \left(\rho c_{p}\right)_{n f}=(1-\phi)\left(\rho c_{p}\right)_{f}+\phi\left(\rho c_{p}\right)_{s}, \frac{k_{n f}}{k_{f}}=\frac{\left(k_{s}+2 k_{f}\right)-2 \phi\left(k_{f}-k_{s}\right)}{\left(k_{s}+2 k_{f}\right)+2 \phi\left(k_{f}-k_{s}\right)} .
\end{aligned}
$$

In the open literature different correlations exist for the electrical conductivity of nanofluids. Correlations which are functions of particle size, temperature and solid particle volume fractions were also developed. Very recently, Selimefendigil and Oztop ([21]) utilized Maxwell's electrical conductivity model which is used to calculate the effective electrical conductivity of a random suspension of spherical nanoparticles. In this study, the electrical conductivity of the nanofluid is a linear interpolation of base fluid and nanoparticle volume fraction is utilized and is given by:

$(\sigma)_{n f}=(1-\phi)(\sigma)_{f}+\phi(\sigma)_{s}$

Where $\phi$ is the solid volume fraction of the nanofluid, $\rho_{f}$ is the reference density of the fluid fraction, $\rho_{s}$ is the reference density of the solid fraction, $\mu_{f}$ is the viscosity of the fluid fraction, $\beta_{f}$ thermal expansion coefficient of the fluid, $\beta_{s}$ is the thermal expansion coefficient of the nanoparticles, $k_{s}$ is the thermal conductivity of the solid fraction, $k_{f}$ is the electrical conductivity of the fluid and $k_{n f}$ is the thermal conductivity of the nano fluid. With an assumption for the optically thick boundary layer we adopt Rosseland's diffusion 
approximation for the radiative heat flux $q_{r}$ as given by $q_{r}=-\frac{4 \sigma^{*}}{3 k^{*}} \frac{\partial T^{4}}{\partial y}$, where $\sigma^{*}$ is the Stephen-Boltzmann constant and $k^{*}$ is the Rosseland mean absorption coefficient. The term $T^{4}$ due to radiation can be expressed as a linear function of temperature itself. Therefore, $T^{4}$ can be approximated by Taylor's series about $T_{\infty}$ after neglecting the higher order terms as $T^{4}=4 T_{\infty}^{3} T-3 T_{\infty}^{4}$. Therefore via substituting $\frac{\partial q_{r}}{\partial y}=-\frac{16 \sigma^{*} T_{\infty}^{3}}{3 k^{*}} \frac{\partial^{2} T}{\partial y^{2}}$ in the energy conservation Eq. (3) the following form of the equation emerges:

$$
\begin{aligned}
u \frac{\partial T}{\partial x}+v \frac{\partial T}{\partial y}=\frac{\mu_{n f}}{\rho_{n f}} \frac{\partial^{2} T}{\partial y^{2}} & +\frac{1}{\left(\rho c_{p}\right)_{n f}} \frac{16 \sigma^{*} T_{\infty}^{3}}{3 k^{*}} \frac{\partial^{2} T}{\partial y^{2}} \\
& +\frac{\mu_{n f}}{\left(\rho c_{p}\right)_{n f}}\left(\frac{\partial u}{\partial y}\right)^{2}+\frac{Q_{0}}{\left(\rho c_{p}\right)_{n f}}\left(T_{w}-T_{\infty}\right)
\end{aligned}
$$

Proceeding with the analysis, it is pertinent to introduce the following similarity transformations:

$\psi=\left[\frac{2 v_{f} x u_{w}(x)}{(m+1)}\right]^{1 / 2} f(\eta), \eta=\left[\frac{(m+1) u_{w}(x)}{2 v_{f} x}\right] y, \theta(\eta)=\frac{T-T_{\infty}}{T_{w}-T_{\infty}}, n=2 m$

Where, $v_{f}$ is the kinematic viscosity of the fluid and the stream function $\psi$ is defined as $u=\frac{\partial \psi}{\partial y}, v=-\frac{\partial \psi}{\partial x}$ which identically satisfies the Eq. (1).

Now by substituting Eq. (7) and the aforementioned nanofluid properties into the Eqs. (2), (6) and the corresponding boundary conditions of the problem considered in Eq. (4), the governing boundary layer equations reduce to the following system of highly coupled nonlinear ordinary differential equations, in terms of a single independent variable $(\eta)$ :

$$
\begin{aligned}
& f^{\prime \prime \prime}+(1-\phi)^{2.5}\left\{\begin{array}{l}
\left.(1-\phi)+\phi \frac{\rho_{s}}{\rho_{f}}\right)\left(f f^{\prime \prime}-\frac{2 m}{m+1} f^{\prime 2}\right)-M f^{\prime}+ \\
\frac{2}{m+1}\left((1-\phi)+\phi \frac{(\rho \beta)_{s}}{(\rho \beta)_{f}}\right)(R i \cos (\alpha)) \theta
\end{array}\right\}=0 \\
& \frac{1}{\operatorname{Pr}_{e f f}} \theta^{\prime \prime}+\left((1-\phi)+\phi \frac{\left(\rho c_{p}\right)_{s}}{\left(\rho c_{p}\right)_{f}}\right)\left(\left(\frac{2 m+1}{m+1}\right) f \theta^{\prime}-\left(\frac{4 m}{m+1}\right) f^{\prime} \theta\right)+ \\
& \frac{E c}{(1-\phi)^{2.5}}\left(f^{\prime \prime}\right)^{2}+\frac{1}{m+1} \frac{Q}{\operatorname{Pr}} \theta=0
\end{aligned}
$$

The corresponding transformed boundary conditions for the stretching/shrinking sheet flow are given by: 


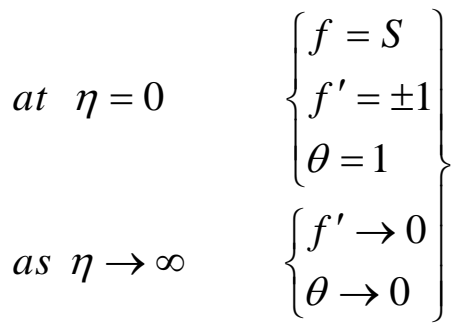

Where $M=\frac{2 \sigma_{n f} B_{0}^{2}}{c(m+1) \rho_{f}}$ is the magnetic field parameter, $R i=\frac{G r}{\operatorname{Re}_{x}^{2}}$ is the Richardson number, $G r=\frac{g \beta\left(T_{w}-T_{\infty}\right) x^{3}}{v_{f}^{2}}$ is the local Grashof number, $\operatorname{Re}_{x}=x u_{w}(x) / v_{f}$ is the local Reynolds number based on the stretching/shrinking velocity $u_{w}(x), E c=\frac{u_{w}^{2}}{\left(c_{p}\right)_{f}\left(T_{w}-T_{\infty}\right)}$ is the Eckert number, $\operatorname{Pr}_{e f f}=\frac{\operatorname{Pr}}{\left(\frac{k_{n f}}{k_{f}}+N r\right)}$ is the effective Prandtl number (Magyari and Pantokratoras [47]), $S=-\frac{2 v_{w} x^{-(m-1) / 2}}{(m+1) \sqrt{c v_{f}}}$ is the mass flux parameter which is either $S>0$ for suction or $S<0$ for injection, $N r=-\frac{16 \sigma^{*} T_{\infty}^{3}}{3 k_{f} k^{*}}$ is the radiation-conduction parameter and $Q=\frac{Q_{0} 2 v_{f} x}{k_{f} u_{w}(x)}$ is the heat source/sink parameter. Furthermore, the physical quantities of engineering interest in materials processing operations are the skin friction coefficient $C_{f}$ or the shear stress and the local Nusselt number or heat transfer coefficient $N u_{x}$ which may be defined by:

$C_{f}=\frac{\mu_{n f}}{\rho_{f} u_{w}^{2}}\left(\frac{\partial u}{\partial y}\right)_{y=0}, N u_{x}=\frac{-x k_{n f}}{k_{f}\left(T_{w}-T_{\infty}\right)}\left(-\frac{\partial T}{\partial y}\right)_{y=0}$

Using Eq. (7) and Eq. (11) the local skin friction coefficient and the local Nusselt number can be expressed as

$\operatorname{Re}_{x}^{1 / 2} C_{f}=\frac{1}{(1-\phi)^{2.5}}\left(\frac{m+1}{2}\right)^{1 / 2} f^{\prime \prime}(0), \operatorname{Re}_{x}^{-1 / 2} N u_{x}=-\frac{k_{n f}}{k_{f}}\left(\frac{m+1}{2}\right)^{1 / 2} \theta^{\prime}(0)$

\section{NUMERICAL SOLUTION OF NONLINEAR BOUNDARY VALUE PROBLEM}

The system of nonlinear coupled and inhomogeneous ordinary differential equations Eq. (8) and Eq. (9) subject to the boundary conditions in Eq. (10) are solved numerically using an implicit finite difference scheme known as the Keller-Box method [48]. Furthermore, this method is found to be suitable in dealing with nonlinear parabolic partial differential equations. It has been implemented in an extensive range of nanofluid and magnetohydrodynamic transport problems and readers are referred to [48]-[52]. Further 
details of this method are available for convection flows in the monograph of Cebeci and Bradshaw ([53]). This method has four fundamental steps.

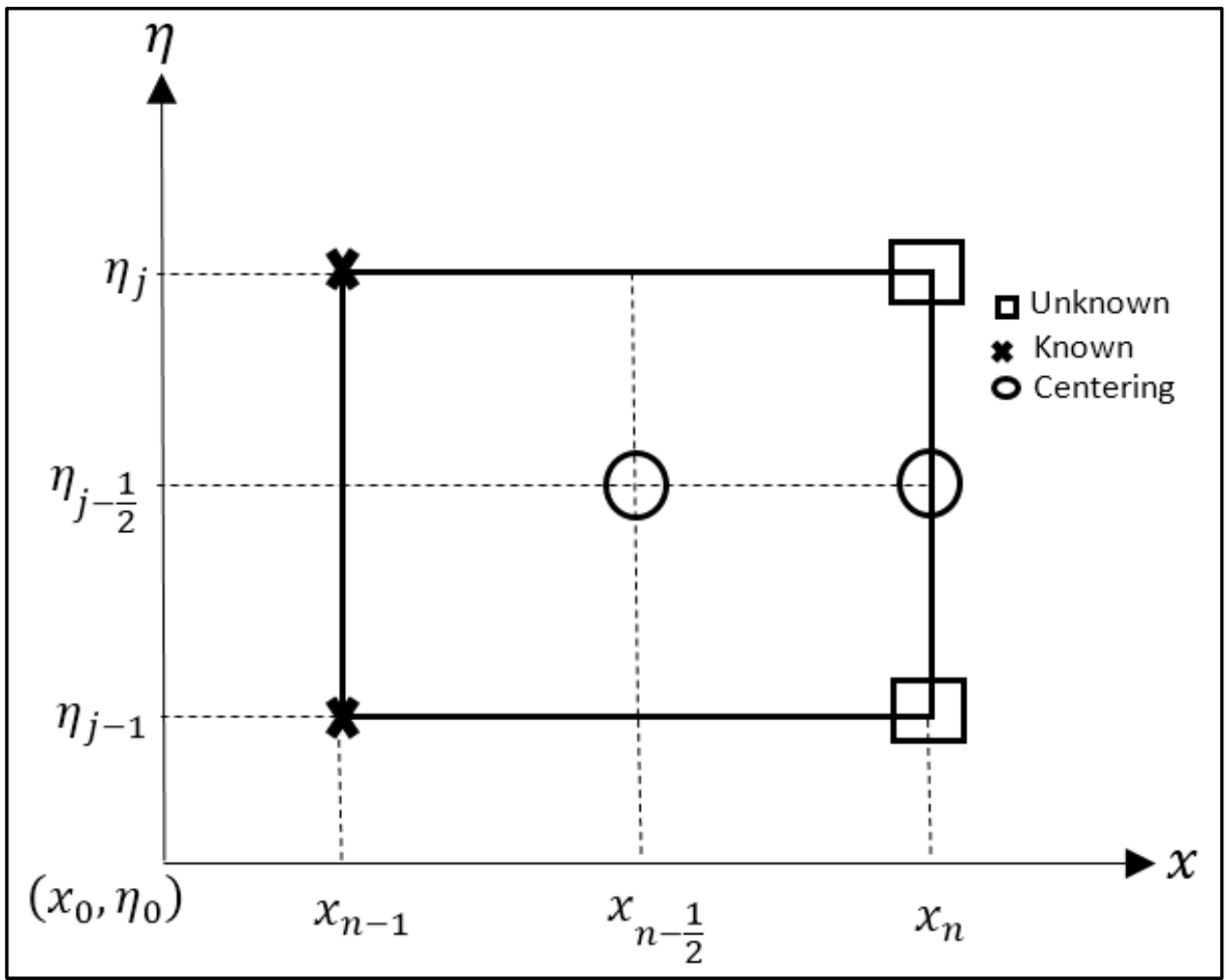

Fig. 2. Net rectangle for finite difference approximation

The first step involves converting the Eqs. (8) - (9) into a system of first order ordinary differential equations. Thus, the coupled differential equations of third order in $f(\eta)$ and second order in $\theta(\eta)$ has been reduced to a system of five simultaneous equations of first order for five unknowns as follows.

$$
\begin{gathered}
f^{\prime}(\eta)=p ; p^{\prime}(\eta)=q ; \theta^{\prime}(\eta)=t \\
q^{\prime}(\eta)=(1-\phi)^{2.5}\left((1-\phi)+\phi\left(\frac{\rho_{s}}{\rho_{f}}\right)\right)\left(\frac{2 m}{m+1} p^{2}-f q\right) \\
+M p-\frac{2}{m+1}\left((1-\phi)+\phi\left(\frac{(\rho \beta)_{s}}{(\rho \beta)_{f}}\right)\right) \operatorname{Ri} \operatorname{Cos}(\alpha) \theta \\
t^{\prime}(\eta)=\operatorname{Pr}_{\text {eff }}\left(\begin{array}{l}
\left.\left.(1-\phi)+\phi\left(\frac{\left(\rho c_{p}\right)_{s}}{\left(\rho c_{p}\right)_{f}}\right)\right)\left(\left(\frac{4 m}{m+1}\right) p \theta-\left(\frac{2 m+1}{m+1}\right) f t\right)\right) \\
-\left(\frac{E c}{(1-\phi)^{2.5}}\right) q^{2}-\left(\frac{1}{m+1} \frac{Q}{\operatorname{Pr}}\right) \theta
\end{array}\right)
\end{gathered}
$$

In the second step derivatives are approximated in the new system of first order equations with central difference approximations by considering the net rectangle in the $x \eta$-planeas shown in Fig. 2 and the net points are defined as $x_{0}=0, x_{n}=x_{n-1}+k_{n}, \eta_{0}=0, \eta_{j}=\eta_{j-1}+h_{j}$ 
$n=1,2,3 \ldots J ; j=1,2,3 \ldots J$ and $\eta_{j}=\eta_{\infty}$. Here $k_{n}$ is the $\Delta x$-spacing and $h_{j}$ is the $\Delta \eta-$ spacing and $n, j$ are just the sequences of numbers that indicate the coordinate location. The centering midpoint $\left(x_{n-\frac{1}{2}}, \eta_{j-\frac{1}{2}}\right)$ of the segment are obtained by using the following finite difference approximations.

$$
\begin{aligned}
& ()_{j}^{n-\frac{1}{2}}=\frac{1}{2}\left[()_{j}^{n}+()_{j}^{n-1}\right] ; \quad\left(\frac{\partial()}{\partial x}\right)_{j-\frac{1}{2}}^{n-\frac{1}{2}}=\frac{1}{k_{n}}\left[()_{j-\frac{1}{2}}^{n}+()_{j-\frac{1}{2}}^{n-1}\right] ; \\
& ()_{j-\frac{1}{2}}^{n}=\frac{1}{2}\left[()_{j}^{n}+()_{j-1}^{n}\right] ;\left(\frac{\partial()}{\partial \eta}\right)_{j-\frac{1}{2}}^{n-\frac{1}{2}}=\frac{1}{h_{j}}\left[()_{j}^{n-\frac{1}{2}}+()_{j-1}^{n-\frac{1}{2}}\right] ;
\end{aligned}
$$

In the third step the emerging nonlinear algebraic equations are linearized with Newton's method by using iterates of the form ()$_{j}^{i+1}=()_{j}^{i}+\delta()_{j}^{i}$ and then cast into matrix vector form. Finally, the linearized algebraic equations are solved using a block tri-diagonal elimination scheme implemented in MATLAB software with the suitable initial solution. This method is unconditionally stable (Cebeci and Bradshaw [53]), has a second order accuracy and is relatively easy to program, thus making it highly attractive for engineering analysis. For this iterative scheme to solve the system of equations, a convergence criterion is required. This is specified as follows: when the difference between two successive approximations is sufficiently small $\left(\leq 10^{-5}\right)$ the solutions are taken to have converged to the requisite accuracy. Mathematical details are omitted for brevity.

Table 1: Thermo-physical properties of water and nanoparticles

\begin{tabular}{cccc}
\hline Physical properties & $\mathrm{H}_{2} \mathrm{O}$ & $\mathrm{Cu}$ & $\mathrm{Al}_{2} \mathrm{O}_{3}$ \\
\hline$C p(\mathrm{j} / \mathrm{kg} \mathrm{k})$ & 4179 & 385 & 765 \\
$\rho(\mathrm{kg} / \mathrm{m} 3)$ & 997.1 & 8933 & 3970 \\
$K(\mathrm{~W} / \mathrm{m} k)$ & 0.613 & 401 & 40 \\
$\beta \times 10^{-5}(1 / \mathrm{k})$ & 21 & 1.67 & 0.85 \\
$\sigma(\mathrm{S} / \mathrm{m})$ & $5.5 \times 10^{-6}$ & $59.6 \times 10^{6}$ & $35 \times 10^{6}$ \\
\hline
\end{tabular}

In the computations, the thermo-physical properties of water and metal nanoparticles $\left(\mathrm{H}_{2} \mathrm{O}\right.$, $\mathrm{Cu}$ and $\mathrm{Al}_{2} \mathrm{O}_{3}$ ) are specified according to Table 1 (Khan et al. [40].)

\section{GRID INDEPENDENCE STUDY}

In order to ensure the obtained numerical solutions are independent of mesh density i.e. grid specification, the effects of grid size on the solutions are studied. The boundary conditions for $y$ at $\infty$ are replaced by a sufficiently large value where the velocity and temperature profiles approach to zero. The MATLAB code is run with three different grid

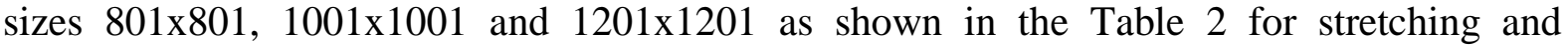
shrinking sheet cases and in each case very good agreement is observed between the profiles. Finally, in the present study, the far field boundary condition $\eta_{\infty}$ is replaced by a sufficiently large value $\eta_{\max }=10$ and for all the computations in this numerical study the adopted grid size is $1001 \times 1001$ with step size of 0.001 . 
Table 2. Grid independence study for different grid sizes when $\phi=0.05$

\begin{tabular}{|c|c|c|c|c|c|c|c|c|c|c|c|}
\hline \multicolumn{6}{|c|}{$f^{\prime}(\eta)$ : Velocity Profiles } & \multicolumn{6}{|c|}{$\theta(\eta):$ Temperature Profiles } \\
\hline \multicolumn{3}{|c|}{$f^{\prime}=+1$} & \multicolumn{3}{|c|}{$f^{\prime}=-1$} & \multicolumn{3}{|c|}{$f^{\prime}=+1$} & \multicolumn{3}{|c|}{$f^{\prime}=-1$} \\
\hline 801 & 1001 & 1201 & 801 & 1001 & 1201 & 801 & 1001 & 1201 & 801 & 1001 & 1201 \\
\hline 1 & 1 & 1 & -1 & -1 & -1 & 1 & 1 & 1 & 1 & 1 & 1 \\
\hline 0.9794 & 0.9794 & 0.9794 & -0.9966 & -0.9966 & -0.9966 & 0.9953 & 0.9953 & 0.9953 & 0.9964 & 0.9964 & 0.9964 \\
\hline 0.9597 & 0.9597 & 0.9597 & -0.9931 & -0.9931 & -0.9931 & 0.9904 & 0.9904 & 0.9904 & 0.9929 & 0.9929 & 0.9929 \\
\hline 0.941 & 0.941 & 0.941 & -0.9897 & -0.9897 & -0.9897 & 0.9856 & 0.9856 & 0.9856 & 0.9893 & 0.9893 & 0.9893 \\
\hline 0.9232 & 0.9232 & 0.9232 & -0.9863 & -0.9863 & -0.9863 & 0.9806 & 0.9806 & 0.9806 & 0.9858 & 0.9858 & 0.9858 \\
\hline 0.9061 & 0.9061 & 0.9061 & -0.9829 & -0.9829 & -0.9829 & 0.9756 & 0.9756 & 0.9756 & 0.9822 & 0.9822 & 0.9822 \\
\hline 0.8897 & 0.8897 & 0.8897 & -0.9795 & -0.9795 & -0.9795 & 0.9706 & 0.9706 & 0.9706 & 0.9787 & 0.9787 & 0.9787 \\
\hline 0.874 & 0.874 & 0.874 & -0.9761 & -0.9761 & -0.9761 & 0.9655 & 0.9655 & 0.9655 & 0.9752 & 0.9752 & 0.9752 \\
\hline 0.8588 & 0.8588 & 0.8588 & -0.9727 & -0.9727 & -0.9727 & 0.9604 & 0.9604 & 0.9604 & 0.9717 & 0.9717 & 0.9717 \\
\hline 0.8443 & 0.8443 & 0.8443 & -0.9693 & -0.9693 & -0.9693 & 0.9553 & 0.9553 & 0.9553 & 0.9682 & 0.9682 & 0.9682 \\
\hline
\end{tabular}

\section{VALIDATION OF NUMERICAL RESULTS}

To ascertain the correctness of the numerical values obtained through the implicit finite difference scheme, a comparison of skin friction coefficient and Nusselt number is made with results obtained through the numerical scheme in some limiting cases. For various values of power law exponent parameter, values of $-f^{\prime \prime}(0)$ and $-\theta^{\prime}(0)$ with $E c=0$ and $E c=0.1$ are compared in the absence of heat source/sink parameter and are documented in Table 3 . This allows verification of the Keller box solutions with those reported by Hamad and Ferdows [34] for a stretching sheet case.

Furthermore, a comparison is also made for the case of absence of heat source/sink for horizontal stagnation point flow over a stretching/shrinking sheet which corresponds to the case studied by Pal et al. [46] wherein the Runge-Kutta RKF45 method with a shooting technique was employed. These comparisons are presented quantitatively in Table 4. It is evident from Table 3 that present the Keller box finite difference numerical values correlate closely with the solutions obtained by Hamad and Ferdows [34] which confirms the accuracy of the present results. Very good correlation is also achieved for both the shrinking and stretching sheet cases with the solutions of Pal et al. [45] in Table 4. Confidence in the present Keller box solutions is therefore justifiably high.

Table 3. Comparison of $-f^{\prime \prime}(0)$ for various values of $m$ and $-\theta^{\prime}(0)$ for several values of $m$ and $E c$ when $\operatorname{Pr}=5.0, M=0, R i=0, N r=0, Q=0 \phi=0$ and $\alpha=\pi / 2$ for a stretching sheet

\begin{tabular}{cccccccc}
\hline & \multicolumn{2}{c}{$-f^{\prime \prime}(0)$} & & \multicolumn{3}{c}{$-\theta^{\prime}(0)$} \\
$m$ & $\begin{array}{c}\text { Hamad and Ferdows } \\
{[34]}\end{array}$ & $\begin{array}{c}\text { Present } \\
\text { results }\end{array}$ & $m$ & $\begin{array}{c}\text { Hamad and Ferdows } \\
{[34]}\end{array}$ & $\begin{array}{c}\text { Present } \\
\text { results }\end{array}$ & $\begin{array}{c}\text { Hamad and Ferdows } \\
{[34]}\end{array}$ & $\begin{array}{c}\text { Present } \\
\text { results }\end{array}$ \\
\hline 0.5 & 0.8897 & 0.88976 & 0.75 & 3.1246 & 3.12463 & 3.0156 & 3.01562 \\
1 & 1.0043 & 1.00457 & 1.5 & 3.5672 & 3.56735 & 3.4566 & 3.45661 \\
3 & 1.1481 & 1.14812 & 7 & 4.1848 & 4.1851 & 4.1354 & 4.13562 \\
\hline
\end{tabular}


Table 4 Comparison of Skin friction and Nusselt number for various values of $\operatorname{Pr}_{\text {eff }}$ when

$$
Q=0 \text { and } \alpha=\pi / 2
$$

\begin{tabular}{ccccccccc}
\hline & \multicolumn{4}{c}{ Stretching sheet } & \multicolumn{3}{c}{ Shrinking sheet } \\
$\operatorname{Pr}_{\text {eff }}$ & \multicolumn{2}{c}{ Dulal Pal et al. $[45]$} & \multicolumn{2}{c}{ Present results } & \multicolumn{2}{c}{ Dulal Pal et al. [45] } & \multicolumn{2}{c}{ Present results } \\
& $f^{\prime \prime}(0)$ & $-\theta^{\prime}(0)$ & $f^{\prime \prime}(0)$ & $-\theta^{\prime}(0)$ & $f^{\prime \prime}(0)$ & $-\theta^{\prime}(0)$ & $f^{\prime \prime}(0)$ & $-\theta^{\prime}(0)$ \\
\hline 2.5 & -1.0721 & 2.3838 & -1.07211 & 2.38389 & 6.1208 & 12.900 & 6.12084 & 12.90123 \\
3.0 & -0.8389 & 1.6065 & -0.83898 & 1.60654 & 0.5687 & 5.8575 & 0.56872 & 5.85756 \\
3.5 & -0.8413 & 1.7548 & -0.84135 & 1.75486 & 0.6223 & 6.8193 & 0.62236 & 6.81931 \\
\hline
\end{tabular}

Table 5 Values of Skin friction and Nusselt number for various values of $S, Q$ and $E c$ when

$$
\operatorname{Pr}_{e f f}=2.5
$$

\begin{tabular}{ccccccc}
\hline \multirow{2}{*}{$S$} & $Q$ & $E$ & \multicolumn{2}{c}{ Stretching Sheet } & \multicolumn{2}{c}{ Shrinking Sheet } \\
& & & $\mathrm{Re}_{x}^{1 / 2} C_{f}$ & $\mathrm{Re}_{x}^{-1 / 2} N u_{x}$ & $\mathrm{Re}_{x}^{1 / 2} C_{f}$ & $\mathrm{Re}_{x}^{-1 / 2} N u_{x}$ \\
\hline $\mathbf{0 . 2 5}$ & $\mathbf{0 . 5}$ & 0.01 & -32.514 & 3.6879 & 1.6029 & 2.1036 \\
0.25 & $\mathbf{1}$ & 0.01 & -32.514 & 3.7859 & 1.5682 & 2.3841 \\
0.25 & $\mathbf{1 . 5}$ & 0.01 & -32.514 & 3.879 & 1.5337 & 2.641 \\
0.25 & $\mathbf{2}$ & 0.01 & -32.514 & 3.9681 & 1.4994 & 2.8782 \\
0.25 & 1.5 & $\mathbf{0 . 1}$ & -32.514 & 3.7859 & 1.5682 & 2.641 \\
0.25 & 1.5 & $\mathbf{0 . 2}$ & -32.514 & 3.1979 & 1.5683 & 2.2213 \\
0.25 & 1.5 & $\mathbf{0 . 3}$ & -32.514 & 2.6099 & 1.5683 & 1.8017 \\
0.25 & 1.5 & $\mathbf{0 . 4}$ & -32.514 & 2.0219 & 1.5684 & 1.3821 \\
$\mathbf{0 . 7 5}$ & $\mathbf{0 . 5}$ & 0.01 & -34.0052 & 4.693 & 1.8148 & 4.856 \\
0.75 & $\mathbf{1}$ & 0.01 & -34.0052 & 4.7794 & 1.7754 & 5.0094 \\
0.75 & $\mathbf{1 . 5}$ & 0.01 & -34.0052 & 4.863 & 1.7361 & 5.1567 \\
0.75 & $\mathbf{2}$ & 0.01 & -34.0052 & 4.9441 & 1.6971 & 5.2983 \\
0.75 & 1.5 & $\mathbf{0 . 1}$ & -34.0052 & 4.7794 & 1.7754 & 5.1567 \\
0.75 & 1.5 & $\mathbf{0 . 2}$ & -34.0052 & 3.9634 & 1.7755 & 4.6894 \\
0.75 & 1.5 & $\mathbf{0 . 3}$ & -34.0052 & 3.1475 & 1.7756 & 4.2221 \\
0.75 & 1.5 & $\mathbf{0 . 4}$ & -34.0052 & 2.3315 & 1.7756 & 3.7548 \\
\hline
\end{tabular}

Additionally in Table 5 computations are provided for the variation of skin friction $\operatorname{Re}_{x}^{1 / 2} C_{f}$ and Nusselt number (wall heat transfer rate) i.e. $\operatorname{Re}_{x}^{1 / 2} N u_{x}$ for both the stretching sheet and shrinking sheet cases, with variation in suction parameter $(S>0)$, heat source $(Q>0)$ and Eckert number $(E c)$. For the stretching sheet case (extending sheet), skin friction is decreased with increasing suction i.e. the flow is decelerated. Conversely skin friction is enhanced for the shrinking sheet case with greater suction. With greater heat source i.e. heat generation, Nusselt number is enhanced for both the stretching sheet and shrinking sheet cases, however the enhancement is much greater for the shrinking sheet case. With increasing Eckert number the skin friction is not influenced tangibly for the stretching sheet case. However a significant reduction in Nusselt number arises for the stretching sheet with greater Eckert number and a weaker decrease is observed for the shrinking sheet case over the same range of variation in Eckert number. The conversion of kinetic energy into thermal energy via viscous heating enhances temperatures in the boundary layer. This serves to heat the nanofluid and decreases the rate of heat transfer at the sheet surface (wall) manifesting in a fall in Nusselt numbers for both the shrinking or stretching scenarios. These trends are 
consistent with other studies including Rana et al. [12] and Pal et al. [45]. The solutions in Table 5 also provide a useful benchmark for other researchers who may wish to extend the present model and validate different numerical procedures against the present Keller box computations.

\section{RESULTS AND DISCUSSION}

Comprehensive numerical computations have been carried out to study the effects of diverse parameters on thermo-fluid characteristics in the nanofluid boundary layer regime. Graphical distributions of the influence of magnetic field parameter $(M)$, volume fraction parameter $(\phi)$, suction parameter $(\mathrm{S})$, power law stretching parameter $(\mathrm{m})$, inclination angle $(\alpha)$, effective Prandtl number $\left(\operatorname{Pr}_{e f f}\right)$, Eckert number $(E c)$ and Richardson number $(R i)$ on velocity, temperature, local skin friction $\left(\operatorname{Re}_{x}^{1 / 2} C_{f}\right)$ and local Nusselt number $\left(\operatorname{Re}_{x}^{-1 / 2} N u_{x}\right)$ profiles are presented in Figs. 3 - 34. In this paper we computed the results for the above physical parameters by fixing the value $\phi=0.05, \operatorname{Pr}=6.8, N r=1.0$ and the parameter values for which the numerical computations are carried out are presented in the respective figure legends. Furthermore, The CPU took 6.52 seconds to compute the velocity profiles and 5.37 seconds to compute the temperature profiles for 1001 nodal points with the Intel core i3 processor under windows platform, which are computed by using the Matlab command tic; \{ Statements ....... toc;.

Two different water based nanofluids $\mathrm{Cu}-\mathrm{H}_{2} \mathrm{O}$ and $\mathrm{Al}_{2} \mathrm{O}_{3}-\mathrm{H}_{2} \mathrm{O}$ are considered for both the stretching sheet $\left(f^{\prime}=+1\right)$ and the shrinking sheet $\left(f^{\prime}=-1\right)$ cases for velocity and temperature profiles. It is worth mentioning here that the momentum boundary layer thickness for $\mathrm{Cu}-\mathrm{H}_{2} \mathrm{O}$ nanofluid is greater than the other water based nanofluid $\mathrm{Al}_{2} \mathrm{O}_{3}-\mathrm{H}_{2} \mathrm{O}$ and this is attributable to the higher density of $\mathrm{Cu}$ compared with $\mathrm{Al}_{2} \mathrm{O}_{3}$. The velocity profiles for stretching sheet/shrinking sheet commence with the surface velocity and decay to zero asymptotically at a distance sufficiently far from the plate surface. Furthermore, the velocity and temperature distributions for $\mathrm{Cu}-\mathrm{H}_{2} \mathrm{O}$ exceed those of the $\mathrm{Al}_{2} \mathrm{O}_{3}-\mathrm{H}_{2} \mathrm{O}$ profiles, and this is associated with the high thermal conductivity of $\mathrm{Cu}$ relative to $\mathrm{Al}_{2} \mathrm{O}_{3}$ which in turn leads to lower momentum boundary layer thickness and higher thermal boundary layer thickness of $\mathrm{Cu}-\mathrm{H}_{2} \mathrm{O}$ nanofluid compared with $\mathrm{Al}_{2} \mathrm{O}_{3}-\mathrm{H}_{2} \mathrm{O}$ nanofluid.

The impact of transverse magnetic field, as characterized in the magnetic parameter, M, on nanofluid velocity profiles is depicted in Figs. 3 and 4. An increase of magnetic field $M$ parameter in the transverse direction to flow field induces a reduction in the velocity distributions for both cases of a stretching sheet $(c>0)$ and a shrinking sheet $(c<0)$. It is noteworthy that for the stretching sheet case the velocity $f^{\prime}(\eta)$ commences with the sheet velocity and then decays to zero asymptotically at the edge of hydrodynamic boundary layer. However for the shrinking sheet case the velocity $f^{\prime}(\eta)$ starts with sheet velocity, attains a maximum value near the vicinity of sheet surface and thereafter decays to zero in the freestream. Only the stretching sheet case therefore produces a monotonic decay. Effectively the momentum boundary layer thickness increases with an increase in magnetic field i.e. $M$ for water based nanofluids. The deceleration in the boundary layer flow is due to the presence of a Lorentz magnetohydrodynamic drag force which acts perpendicular to the magnetic field. This resistive force inhibits the flow. 
Figs. 5 and 6 respectively present the influence of magnetic field parameter $M$ on temperature distribution for $\mathrm{Cu}-\mathrm{H}_{2} \mathrm{O}$ and $\mathrm{Al}_{2} \mathrm{O}_{3}-\mathrm{H}_{2} \mathrm{O}$. We infer from both Figs. 5 and 6 that temperature profiles are increased with an increase in magnetic field parameter. The supplementary work expended in dragging the nanofluid against the action of the magnetic field is dissipated as thermal energy. This heats the nanofluid, elevates temperatures and also increases thermal boundary layer thickness for both stretching and shrinking sheets. The stretching sheet temperature distribution is a consistent monotonic decay from the wall (sheet) to the freestream (peak temperature is always at the wall), whereas the shrinking sheet case follows a parabolic profile with a peak in temperature some distance from the wall.

Figs. 7-10 illustrate the influence volume fraction $(\phi)$ of spherical shaped nanoparticles on velocity and temperature distributions for stretching and shrinking sheet cases with $\mathrm{Cu}-\mathrm{H}_{2} \mathrm{O}$ and $\mathrm{Al}_{2} \mathrm{O}_{3}-\mathrm{H}_{2} \mathrm{O}$ nanofluids. Whenever $\phi$ increases, the velocity profiles are decreased in Figs. 7 and 8 for both stretching and shrinking sheets and temperature profiles are increased in Figs. 9 and 10 for both stretching and shrinking sheets. However, the thermal conductivity of water based nanofluids increases as the nanoparticle size increases due to the low viscosity of the base fluid which promotes the particle clustering and this in turn leads to interconnecting channels for thermal energy to propagate. Therefore as volume fraction increases the thermal conductivity of water based nanofluid is enhanced. Therefore, momentum boundary layer thickness is decreased and thermal boundary layer thickness is increased. Furthermore, inspection of the graphs demonstrates that the velocity and temperature profiles for $\mathrm{Al}_{2} \mathrm{O}_{3}-\mathrm{H}_{2} \mathrm{O}$ nanofluid are markedly lower in magnitude than that of $\mathrm{Cu}-\mathrm{H}_{2} \mathrm{O}$ nanofluid since $\mathrm{Cu}$ has a significantly higher conductivity than the $\mathrm{Al}_{2} \mathrm{O}_{3}$.

Figs. 11 and 13 present the effect of the sheet power-law parameter $(\mathrm{m})$ on velocity and temperature profiles for $\mathrm{Cu}-\mathrm{H}_{2} \mathrm{O}$ and $\mathrm{Al}_{2} \mathrm{O}_{3}-\mathrm{H}_{2} \mathrm{O}$ nanofluids for the stretching sheet case and Figs. 12 and 14 for the shrinking sheet case. It is observed from Figs. 11 and 12 that the velocity profiles are decreased with an increase of power-law parameter and decay from a maximum at the sheet surface asymptotically to zero in the freestream. Similarly for the shrinking sheet, an increase in power-law parameter decreases the velocities. However the profiles grow from a minimum at the wall to achieve a maximum in the free stream for the shrinking sheet, which is the opposite trend i.e. in Figs. 12 and 14 velocity is consistently decreased with increasing values of $(m)$. Therefore more intensive stretching or shrinking of the sheet induces deceleration in the flow. We infer from Fig. 13 that temperature profiles are decreased near surface of the sheet and increased in the region away from the sheet surface with an increase in power-law parameter. Furthermore Fig. 14 demonstrates that the fluid temperature profiles exhibit a parabolic distribution. In both stretching and shrinking sheet cases, generally the copper-water nanofluid attains higher temperatures than the aluminium oxide water nanofluid.

Figs. 15 and 16 present the nanofluid temperature distributions for both the stretching and shrinking (contracting) sheet cases for different values of heat source parameter $(Q>0)$. We do not consider the heat $\operatorname{sink}(Q<0)$ case. Fig. 15 illustrates that an increase of $Q$ leads to increase in the temperature profiles in the thermal boundary layer regime, owing to the generation of energy in the thermal boundary layer. The nanofluid is energized by the presence of a heat source. Therefore, when heat is absorbed the buoyancy force also accelerates the flow. The stretching sheet temperature profile however follows a monotonic decay from the wall to the free stream. In Fig. 16 although for the shrinking sheet, there is also a boost in temperature profiles with heat source $(\mathrm{Q}>0)$, the profiles consistently exhibit a 
temperature overshoot near the surface of the sheet. This overshoot is displaced progressively further from the sheet surface with greater heat source (generation) which increases the magnitudes of temperatures throughout the boundary layer. Therefore greater heat source serves to increase thermal boundary layer thickness. Again it is evident that copper water nanofluid temperatures exceed those computed for the aluminum oxide water nanofluid case.

Figs. 17 and 18 depict the influence of angle of inclination $(\alpha)$ on the evolution of velocity distributions for both stretching and shrinking sheet cases. It is clearly observed from Fig. 17 that velocity is decreased with an increase of angle of inclination for the stretching sheet case, implying that the nanofluid experiences increased drag at the sheet surface. Furthermore, the buoyancy effects decrease by a factor of gravity component $\cos (\alpha)$ as the inclination angle is increased. Hence the fluid attains higher magnitudes of velocity for the vertical stretching sheet case compared with the inclined stretching sheet. Magnitudes are consistently positive however indicating that backflow is never attained at any angle of inclination. Consequently, momentum boundary layer thickness increases with greater inclination of the sheet. Similarly Fig. 18 shows that with increasing inclination angle, the shrinking sheet flow is also decelerated i.e. smaller magnitudes of velocity are computed. The decrease in buoyancy force therefore also decelerates the flow for the shrinking sheet case; however the shrinking sheet exhibits consistently negative values corresponding to flow reversal, a trend which is not observed in the stretching sheet case.

Figs. 19 and 20 present the effect of Richardson number $(R i)$ on the velocity profiles for both the stretching and shrinking sheet cases. The heat and cooling of the sheet surface and absence of free convection currents are physically represented by different values of Richardson number, specifically $R i>0, R i<0$ and $R i=0$ respectively. By increasing the Richardson number, the thermal buoyancy force term is increased in Eqn. (8) i.e. the momentum equation. Fig. 19 demonstrates that the velocity profiles are increased for stretching sheet case whereas Fig. 20 clearly indicates the opposite i.e. that the nanofluid flow is decelerated for the shrinking sheet case with greater Richardson number i.e. values are increasingly negative for velocity. If the Richardson number is much less than unity, buoyancy is relatively insignificant. If it is much greater than unity, buoyancy is dominant. If the Richardson number is of order unity, as considered in the present graphs, the flow is buoyancy-driven: the energy of the flow derives from the potential energy in the system originally. The larger buoyancy force caused by greater Richardson number serves to accelerate the flow in a stretching sheet whereas it decelerates the flow in a shrinking sheet. Buoyancy therefore exerts a very profound effect on the flow development for the different scenarios of stretching and shrinking. In general the copper-water nanofluid achieves better acceleration than the aluminium-water nanofluid.

The influence of suction parameter $(S)$ on velocity profiles in the cases of stretching and shrinking sheet cases are shown in Figs. 21 and 22 respectively. The velocity profiles for water based nanofluids $\mathrm{Cu}-\mathrm{H}_{2} \mathrm{O}$ and $\mathrm{Al}_{2} \mathrm{O}_{3}-\mathrm{H}_{2} \mathrm{O}$ decrease with an increase of the suction parameter for the stretching sheet whereas they increase for the shrinking sheet. The increase in suction draws nanofluid laterally through the sheet surface. This generates an adherence of the nanofluid boundary layer to the stretching sheet, destroys momentum in the fluid near the sheet surface and consequently stabilizes the momentum boundary layer growth. Therefore, nanofluid momentum boundary layer thickness is increased with greater suction as shown in Fig. 21. Conversely for the shrinking sheet (Fig. 22) the flow is accelerated with greater suction (less negative velocity values arise) and this decreases momentum boundary layer thickness. As a result, suction can be used effectively for controlling the momentum 
boundary layer growth/decay by using stretching/shrinking sheets respectively. Again copper water nanofluid achieves better flow acceleration than the aluminium oxide water nanofluid.

Figs. 23 and 24 illustrate the influence of Eckert number (Ec) on temperature profiles. The correlation between the kinetic energy in the flow and the boundary layer enthalpy difference is simulated via Eckert number. Due to internal friction heating between molecules of the fluid, mechanical energy is converted to thermal energy which heats the fluid in stretching sheet flow (Fig. 23). Therefore, an increase in Eckert number causes an increase in thermal energy contributing to the flow and will enhance the temperature of the water based nanofluids in the stretching sheet and also manifest in greater thermal boundary layer thickness. However the nature of shrinking sheet flow (contraction of the nanofluid sheet) generates the opposite response and temperatures are found to be decreased with greater Eckert number. The impact of viscous dissipation therefore is influenced by the nature of the boundary layer regime- it heats the boundary layer for a stretching sheet whereas it cools the boundary layer for a contracting sheet, and these aspects are of some importance in materials processing operations. However irrespective of whether the sheet is stretching or shrinking (contracting), the copper water nanofluid attains higher temperatures than the aluminium oxide water nanofluid.

Figs. 25 and 26 illustrate the variations in the temperature profiles for different values of effective Prandtl number $\left(\mathrm{Pr}_{\text {eff }}\right)$ for the stretching and shrinking sheet cases respectively. The Prandtl number refers to the relative contribution of momentum diffusion to thermal diffusion in the boundary layer regime. An iincrease in $\operatorname{Pr}_{\text {eff }}$ generally results in a decrease in the temperature distribution in the thermal boundary layer for both stretching and shrinking sheet cases. However very close to the wall (sheet) in the shrinking sheet case there is a shortlived weak increase in temperature profiles. This anomaly is however eliminated very quickly and the dominant trend is for a reduction in temperatures with greater effective Prandtl number. Smaller values of $\operatorname{Pr}_{\text {eff }}$ are equivalent to an increasing thermal conductivity, and therefore heat is able to diffuse away from the heated surface more rapidly than at higher values of $\mathrm{Pr}_{\text {eff }}$. Consequently the rate of heat transfer near the sheet surface is reduced. Therefore, an increase in the value of $\operatorname{Pr}_{\text {eff }}$ causes a reduction in the thickness of the thermal boundary layer for both shrinking and stretching sheet cases. Furthermore the copper water nanofluid attains greater thermal boundary layer thickness than the aluminium oxide water nanofluid case.

Figs. 27-34 illustrate the response in skin friction $\left(\operatorname{Re}_{x}^{1 / 2} C_{f}\right)$ and Nusselt number ( $\left.\operatorname{Re}_{x}^{1 / 2} \mathrm{Nu} u_{x}\right)$ for the $\mathrm{Cu}-\mathrm{H}_{2} \mathrm{O}$ nanofluid, with variation in selected thermo-physical parameters. Figs. 27-28 present, for both stretching and shrinking sheet cases, the values of $\operatorname{Re}_{x}^{1 / 2} C_{f}$ and $\operatorname{Re}_{x}^{1 / 2} N u_{x}$ for suction parameter $(0 \leq S \leq 1)$ vs. the dimensionless parameters which includes $R i, m, \phi$ and $M$. Evidently with increasing $R i$ and $m$ (power law parameter) the values of $\operatorname{Re}_{x}^{1 / 2} C_{f}$ are decreased for stretching sheet case whereas the converse trend is observed for the shrinking sheet case. Fig. 29 demonstrates that the values of $\operatorname{Re}_{x}^{1 / 2} C_{f}$ are decreased for increasing values of $\phi$ and $M$ in the stretching sheet case where as for shrinking sheet case the reverse trend is observed in Fig. 30. It is also evident from Figs. 31 and 33 that the $\operatorname{Re}_{x}^{1 / 2} N u_{x}$ values are decreased with increasing values of $R i$ and $M$ for the stretching sheet case while with increasing values of $\phi$ and $m$ the values of $\operatorname{Re}_{x}^{1 / 2} N u_{x}$ are decreased for the shrinking sheet scenario, initially with lower values of $S$ and thereafter the opposite trend is 
observed for increasing values of $S$ in Figs. 32 and 34. The values of $\operatorname{Re}_{x}^{1 / 2} N u_{x}$ are increased with increasing values of $\phi$ and $m$ for the stretching sheet case in Figs. 31 and 33 while the same trend is observed with increasing values of $R i$ and $M$ for the shrinking sheet case as shown in Figs. 32 and 34. We further note that in all computations the radiative-conductive parameter $(\mathrm{Nr})$ has been fixed and is not explicitly considered.

\section{CONCLUSIONS}

Magnetohydrodynamic radiative mixed convection and dissipative boundary layer flow of nanofluid from a nonlinear inclined stretching/shrinking sheet in the presence of heat source/sink and viscous dissipation has been studied theoretically and numerically in this paper. The governing coupled nonlinear momentum and thermal boundary layer equations are transformed into ordinary differential equations by using local similarity transformations. The emerging nonlinear boundary value problem is solved with the Keller-Box implicit finite difference method. The originality of the present study entails an elaboration of the influence of governing parameters on velocity and temperature distributions for stretching/shrinking sheet cases utilizing two different types of water based nanofluids $\mathrm{Cu}-\mathrm{H}_{2} \mathrm{O}$ and $\mathrm{Al}_{2} \mathrm{O}_{3}-\mathrm{H}_{2} \mathrm{O}$ under nonlinear boundary conditions. Verification of the Keller box solutions has been achieved via comparison with previously published reports and generally very close correlation is observed. The principal findings of the current simulation may be summarized thus:

- The velocity profiles are decreased with increasing values of magnetic field parameter, volume fraction parameter and power-law parameter for both stretching sheet and shrinking sheet cases.

- For the stretching sheet case the velocity profiles are increased with increasing Richardson number and are decreased with increasing suction parameter whereas the opposite trend is computed for the shrinking sheet case.

- The temperature distribution values are increased with greater magnetic field parameter, volume fraction parameter and power-law parameter for both stretching and shrinking sheet cases.

- With increasing Eckert number the temperature values are increased for the stretching sheet case and the opposite trend is observed for the shrinking sheet case.

- With increasing power-law parameter, temperature is decreased initially and then increased with suction parameter.

- With increasing effective Prandtl number, temperature is decreased in the case of a stretching sheet whereas the converse behavior is found for a shrinking sheet case.

- For the stretching sheet case, the skin friction coefficient and local Nusselt number are decreased by decreasing the Richardson number and magnetic field parameter values. Moreover, an increase in the power-law parameter and volume fraction parameter results in a decrease in the skin friction coefficient whereas the reverse trend is observed for the local Nusselt number with increasing power-law parameter and volume fraction parameter.

- For the shrinking sheet case with an increase in Richardson number and magnetic field parameter, the local Nusselt number and skin friction coefficient are both increased. However with increasing power-law parameter and volume fraction parameter values, the skin friction coefficient is increased whereas the local Nusselt number is decreased initially and thereafter increased with suction parameter values. 


\section{Appendix I}

\begin{tabular}{|c|c|}
\hline \multicolumn{2}{|c|}{ Nomenclature } \\
\hline$(u, v)$ & $\begin{array}{l}\text { Velocity components along }(x, y) \text { axes } \\
\left(m s^{-1}\right)\end{array}$ \\
\hline$u_{w}$ & Stretching/Shrinking sheet velocity \\
\hline$\psi$ & Stream function \\
\hline$\eta$ & Similarity variable \\
\hline$f$ & Dimensionless velocity \\
\hline$g$ & Acceleration due to gravity $\left(m s^{-2}\right)$ \\
\hline$m$ & Nonlinear stretching parameter \\
\hline$b$ & Constant \\
\hline$c$ & $\begin{array}{l}\text { Stretching/shrinking parameter } \quad(>0 \text { for } \\
\text { stretching sheet and }<0 \text { for shrinking sheet })\end{array}$ \\
\hline$M$ & Dimensionless magnetic field parameter \\
\hline$S$ & Suction/injection parameter \\
\hline$Q$ & Heat Source/Sink parameter \\
\hline$N r$ & Thermal radiation parameter \\
\hline $\operatorname{Re}_{x}^{2}$ & Reynolds number \\
\hline$R i$ & Richardson number (Buoyancy parameter) \\
\hline$E c$ & Eckert number \\
\hline$N u_{x}$ & Nusselt number \\
\hline $\operatorname{Pr}$ & Prandtl number \\
\hline $\operatorname{Pr}_{\text {eff }}$ & Effective Prandtl number \\
\hline$C_{f}$ & Skin friction coefficient \\
\hline$G r$ & Thermal Grashof number \\
\hline$B$ & External uniform magnetic field \\
\hline Bo & Magnetic field strength \\
\hline$q_{r}$ & Thermal radiative heat flux \\
\hline$K s$ & $\begin{array}{l}\text { Thermal conductivity of the solid } \\
\left(W m^{-1} K^{-1}\right)\end{array}$ \\
\hline$K_{f}$ & $\begin{array}{l}\text { Thermal conductivity of the fluid } \\
\left(W m^{-1} K^{-1}\right)\end{array}$ \\
\hline$K_{n f}$ & $\begin{array}{l}\text { Thermal conductivity of the nanofluid } \\
\left(W m^{-1} K^{-1}\right)\end{array}$ \\
\hline$T$ & Local temperature of the fluid $(K)$ \\
\hline$T_{w}$ & Temperature of the fluid at the wall $(K)$ \\
\hline$T_{\infty}$ & Free stream temperature $(K)$ \\
\hline
\end{tabular}

$k^{*} \quad$ Mean absorption coefficient

\section{Greek symbols}

$\alpha \quad$ Thermal diffusivity coefficient $\left(m^{2} s^{-1}\right)$

$\alpha_{f} \quad$ Thermal diffusivity of the fluid $\left(m^{2} s^{-1}\right)$

$\alpha_{s} \quad$ Thermal diffusivity of the solid $\left(m^{2} s^{-1}\right)$

$\alpha_{n f}$ Thermal diffusivity of the nanofluid $\left(m^{2} s^{-1}\right)$

$\beta \quad$ Thermal expansion coefficient $\left(K^{-1}\right)$

$\beta_{f} \quad$ Coefficient of thermal expansion of the fluid $\left(K^{-1}\right)$

$\beta_{s} \quad$ Coefficient of thermal expansion of the solid $\left(K^{-1}\right)$

$\rho_{f} \quad$ Density of the fluid friction $\left(\mathrm{Kgm}^{-3}\right)$

$\rho_{s} \quad$ Density of the solid friction $\left(\mathrm{Kgm}^{-3}\right)$

$\rho_{n f} \quad$ Density of the nanofluid $\left(\mathrm{Kgm}^{-3}\right)$

$v \quad$ Kinematic viscosity $\left(m^{2} s^{-1}\right)$

$v_{f} \quad$ Kinematic viscosity of the fluid $\left(m^{2} s^{-1}\right)$

$\mu \quad$ Dynamic viscosity $\left(N s m^{-2}\right)$

$\mu_{f} \quad$ Dynamic viscosity of the fluid $\left(N s m^{-2}\right)$

$\mu_{n f} \quad$ Dynamic viscosity of the nanofluid

$$
\left(\mathrm{Nsm}^{-2}\right)
$$

$\sigma \quad$ Electrical conductivity $\left(\mathrm{sm}^{-1}\right)$

$\sigma_{s} \quad$ Electrical conductivity of the solid $\left(\mathrm{sm}^{-1}\right)$

$\sigma_{f} \quad$ Electrical conductivity of the fluid $\left(\mathrm{sm}^{-1}\right)$

$\sigma_{n f} \quad$ Electrical conductivity of the nanofluid $\left(s m^{-1}\right)$

$\sigma^{*} \quad$ Stefan-Boltzmann constant

$c_{p} \quad$ Specific heat at constant pressure

$$
\left(J m^{-3} K^{-1}\right)
$$

$\left(\rho c_{p}\right)_{n f}$ Heat capacitance of the nanofluid $\left(J m^{-3} K^{-1}\right)$ 


$\begin{array}{llcl}\left(\rho c_{p}\right)_{f} & \text { Heat capacitance of the fluid }\left(\mathrm{Jm}^{-3} \mathrm{~K}^{-1}\right) & f & \text { Fluid Phase } \\ \left(\rho c_{p}\right)_{s} & \text { Heat capacitance of the solid }\left(\mathrm{Jm}^{-3} \mathrm{~K}^{-1}\right) & s & \text { Solid phase } \\ \phi \quad \text { Nanoparticle volume fraction parameter } & w & \text { Nanofluid } \\ \theta \quad \text { Non-dimensional temperature } & \infty & \text { Condition at the wall } \\ \text { Subscripts } & & \\ \text { Acknowledgements } & & \end{array}$

The authors are grateful to reviewers for their insightful comments which have served to improve the quality of the present work.

\section{REFERENCES}

[1] S. U. S. Choi, Enhancing thermal conductivity of fluids with nanoparticles, Dev. Appl. Non-Newtonian Flows, ASME Fluids Division, 66 (1995) 99-105.

[2] J. A. Eastman, S. L. S. S. Choi, W. Yu, L. J. Thompson, Anomalously increased effective thermal conductivity of ethylene glycol-based nanofluids containing copper nanoparticles, Appl. Phys. Lett. 78 (2001) 718-720.

[3] Y. Xuan, Q. Lin, Investigation on convective heat transfer and flow features of nanofluids, J. Heat Transfer 125 (2003) 151-155.

[4] F. Selimefendigil, H. F. Oztop, conjugate natural convection in a cavity with a conductive partition and filled with different nanofluids on different sides of the partition, J. of molecular liquids 216 (2016) 67-77.

[5] F. Selimefendigil, H. F. Oztop, MHD mixed convection and entropy generation of power law fluids in a cavity with a partial heater under the effect of rotating cylinder, Int. J. heat and mass transfer 98 (2016) 40-51.

[6] T. Hayat, Q. Sajid, A. Alsaedi, Md. Waqas, Simultaneous influences of mixed convection and non-linear thermal radiation in stagnation point flow of Oldroyd-B fluid towards an unsteady convectively heated stretching surface, J. of Mol. Liq. Part A 224 (2016) 811-817.

[7] F. M. Abbasi, S. A. Shehzad, Heat transfer analysis for three dimensional flow of Maxwell fluid with temperature dependent thermal conductivity: Application of Cattaneo-Christov heat flux model, J. of Mol. Liq. 220 (2016) 848-854.

[8] F. Selimefendigil, H. F. Oztop, Numerical study of MHD mixed convection in a nanofluid filled lid driven square enclosure with a rotating cylinder, Int. J. of Heat and Mass transfer 78 (2014) 741-754.

[9] T. Hayat, Md. Taseer, A. Qayyum, A. Alsaedi, M. Mustafa, On squeezing flow of nanofluid in the presence of magnetic field effects, J. of Mol. Liq. 213 (2016) 179-185.

[10] F. Selimefendigil, H. F. Oztop, K. Al-Salem, Natural convection of ferrofluids in partially heated square enclosures, J. of Magnetism and Magnetic materials 72 (2014) 122-123.

[11] R. Cortell, Viscous flow and heat transfer over a nonlinear stretching sheet, Appl. Math. Computation. 184 (2007) 864-873.

[12] P. Rana, R. Bhargava, O. Anwar Beg, A. Kadir, Finite element analysis of viscoelastic nanofluid flow with energy dissipation and internal heat source/sink effects, Int. J. Applied Computational Mathematics (2016). DOI 10.1007/s40819-016-0184-5 (27 pages)

[13] L.S. Sundar, K.V. Sharma, M.T. Naik, M.K. Singh, Empirical and theoretical correlations on viscosity of nanofluids: A review, Renew. Sust. Energ. Rev. 25 (2013) 670-686. 
[14] K. Khanafer, K. Vafai, A critical synthesis of thermo-physical characteristics of nanofluids, Int. J. Heat Mass Transfer, 54 (2011) 4410-4428.

[15] J. Philip, P.D. Shima, Thermal properties of nanofluids, Adv. Colloid Interface Sci. 183-184 (2012) 30-45.

[16] N. Freidoonimehr, M. M. Rashidi, S. Mahmud, Unsteady MHD free convective flow past a permeable stretching vertical surface in a nano-fluid, Int. J. of thermal science 87 (2015) 136-145.

[17] O. D. Makinde, W. A. Khan, Z. H. Khan, Buoyancy effects on MHD stagnation point flow and heat transfer of a nanofluid past a convectively heated stretching/shrinking sheet, Int. J. Heat Mass Transfer, 62 (2013) 526-533.

[18] O. D. Makinde, F. Mabood, W. A. Khan, M. S. Tshehla, MHD flow of variable viscosity nanofluid over a radially stretching convective surface with radiative heat, J. of Mol. Liq. 219 (2016) 624-630.

[19] F. Selimefendigil, H. F. Oztop, Influence of inclination angle of magnetic field on mixed convection of nanofluid flow over a backward facing step and entropy generation, Advanced Powder Technology 26(6) (2015) 1663-1675

[20] F. Selimefendigil, H. F. Oztop, Mixed convection of nanofluid filled cavity with oscillating lid under the influence of an inclined magnetic field, J. of the Taiwan Institute of Chemical Eng. 63 (2016) 202-2015.

[21] F. Selimefendigil, H. F. Oztop, conjugate natural convection in a nanofluid filled portioned horizontal annulus formed by two isothermal cylinder surfaces under magnetic field, Int. J. of Heat and mass Transfer Part A 108 (2017) 156-171

[22] F. Selimefendigil, H. F. Oztop, A. J. Chamkha, MHD mixed convection and entropy generation of nanofluid filled lid driven cavity under the influence of inclined magnetic fields imposed to its upper and lower diagonal triangular domains, J. of Magnetism and Magnetic materials 406 (2016) 266-281.

[23] T. Hayat, Arsalan Aziz, Taseer Muhammad, Ahmed Alsaedi, On Magnetohydrodynamic three-dimensional flow of nanofluid over a convectively heated nonlinear stretching surface, Int. J. Heat Mass Transfer, 100 (2016) 566-572.

[24] M. H. Abolbashari, N. Freidoonimehr, F. Nazari, M. M. Rashidi, Entropy analysis for an unsteady MHD flow past a stretching permeable surface in nanofluids, Powder Technology 267 (2014) 256-267.

[25] M. M Rashidi, M. Ali, N. Freidoonimehr, B. Rostami, M. A. Hossain, Mixed convective heat transfer for MHD viscoelastic fluid flow over a porous wedge with thermal radiation, Advances in Mechanical. Engineering. (2014) Id: 735939 http://dx.doi.org/ 10.1155/2014/735939.

[26] M. M Rashidi, E. Erfani analytical method for solving steady MHD convective and slip flow due to a rotating disk with viscous dissipation and Ohmic heating, Eng. Computations. Int. J. for computer aided Eng. and software 29 (6) (2012) 562-569.

[27] A. S. Dogonchi, D. D. Ganji, Investigation of MHD nanofluid and heat transfer in a stretching/shrinking convergent/divergent channel considering thermal radiation, J. of Mol. Liq. 220 (2016) 592-603.

[28] A. S. Dogonchi, D. D. Ganji, Thermal radiation effect on the nanofluid buoyancy and heat transfer over a stretching sheet considering Brownian motion, J. of Mol. Liq. 223 (2016) 521-527.

[29] B.C. Sakiadis, Boundary layer behavior on continuous solid surfaces: I. boundary layer equations for two-dimensional and axisymmetric flow, AIChemE J. 7 (1961) 26-28.

[30] B.C. Sakiadis, Boundary layer behavior on continuous solid surfaces: II. The boundary layer on a continuous flat surface, AIChemE J. 7 (1961) 221-225. 
[31] L.J. Crane, Flow past a stretching plate, Z. Angew Math. Phys. 21 (1970) 645-647.

[32] S. Goldstein, on backward boundary layers and flow in converging passages, J. Fluid Mech. 21 (1965) 33-45.

[33] P.S. Gupta, A.S. Gupta, Heat and mass transfer on a stretching sheet with suction or blowing, Can. J. Chem. Eng. 55 (1977) 744-746.

[34] M. A. A. Hamad, M. Ferdows, Similarity solutions to viscous flow and heat transfer of nanofluid over non-linearly stretching sheet, Applied Mathematics and MechanicsEnglish Edition, 33(7) (2012) 923-930.

[35] F. T. Akyildiz, D. A. Siginer, Galerkin-Legendre spectral method for the velocity and thermal boundary layers over a non-linearly stretching sheet. Nonlinear Analysis: Real World Applications, 11 (2010) 735-741.

[36] N. Bachok, A. Ishak, R. Nazar, N. Senu, Stagnation-point flow over a permeable stretching/shrinking sheet in a copper-water nanofluid, Boundary Value Problems, 39 (2013) 1-10.

[37] N. Bachok, A. Ishak, I. Pop, Boundary layer flow and heat and mass transfer over an exponentially stretching/shrinking sheet in a nanofluid, Int. J. Heat and Mass Transfer, 55 (2012) 8122-8128.

[38] P. Rana, R. Bhargava, Flow and Heat and Transfer of a nanofluid over a nonlinearly stretching sheet: A numerical Study, Communication Nonlinear Science Numerical Simulation, 17 (2012) 212-226.

[39] F. Selimefendigil, H. F. Oztop, Mixed convection in a two-sided elastic walled and $\mathrm{SiO} 2$ nanofluid filled cavity with internal heat generation: Effects of inner rotating cylinder and nano particle shape, J. of molecular Liquids 212(2015) 509-516.

[40] W. A. Khan, O. D. Makinde, Z. H. Khan, Non-aligned MHD stagnation point flow of variable viscosity nanofluids past a stretching sheet with radiative heat, Int. J Heat Mass Transfer, 96 (2016) 525-534.

[41] F. Selimefendigil, H. F. Oztop, mixed convection in a partially heated triangular cavity filled with nanofluid having a partially flexible wall and internal heat generation, J. of the Taiwan Institute of Chem. Eng. 70 (2017) 168-178.

[42] Rama Subba Reddy Gorla, B. J. Gireesha, Dual solutions for stagnation point flow and convective heat transfer of a nanofluid past a stretching/shrinking sheet, Heat Mass Transfer. DOI 10.1007/s00231-015-1627-y (2015).

[43] Junaid Ahmed Khan, M. Mustafa, T Hayat, A. Alsaedi, Three-dimensional flow of nanofluid over a non-linearly stretching sheet: An application to solar energy, Int. J. Heat and Mass Transfer, 86 (2015) 158-164.

[44] F. Selimefendigil, H. F. Oztop, Analysis of MHD mixed convection in a flexible walled and nanofluids filled lid driven cavity with volumetric heat generation, Int. J. of Mechanical Sciences 118 (2016) 113-124.

[45] Dulal Pal, Gopinath Mandal, Kuppalapalle Vajravelu, MHD convection-dissipation heat transfer over a non-linear stretching and shrinking sheet in nanofluids with thermal radiation, Int. J. Heat and Mass Transfer, 65 (2013) 481-490.

[46] H.B. Keller, Numerical methods in boundary layer theory, Ann. Rev. Fluid Mech., 10, 417-433 (1978).

[47] E. Magyari, A. Pantokratoras, Note on the effect of thermal radiation in the linearized Rosseland approximation on the heat transfer characteristic of various boundary layer flow, Int. Comm. Heat Mass Transfer 38 (2011) 554-556.

[48] S. A. Gaffar, V. R. Prasad, B. Vijaya, O. Anwar Bég, Mixed convection flow of magnetic viscoelastic polymer from a non-isothermal wedge with Biot number effects, Int. J. Engineering Mathematics, Volume 2015 (2015) Article ID 28762315 pages. 
[49] O. Anwar Bég, S. Abdul Gaffar, V. Ramachandra Prasad, M.J. Uddin, Computational solutions for non-isothermal, nonlinear magneto convection in porous media with Hall/Ion slip currents and Ohmic dissipation, Engineering Science and Technology-an International Journal, 19 (2016) 377-394.

[50] F. Mabood, W. A. Khan, M. M. Yovanovich, Forced convection of nanofluid fluid flow across horizontal cylinder with convective boundary conditions, J. of Mol. Liq. 222 (2016) 172-180.

[51] V.R. Prasad, S. A. Gaffar, O. Anwar Bég, Non-similar computational solutions for free convection boundary-layer flow of a nanofluid from an isothermal sphere in a nonDarcy porous medium, J. Nanofluids, 4 (2015) 1-11.

[52] S. E. Ghasemi, M. Hatami, D. Jing, D. D. Ganji, Nanoparticles effect on MHD fluid flow over a stretching sheet with solar radiation: A numerical study, J. of Mol. Liq. 219 (2016) 890-896.

[53] T. Cebeci, P. Bradshaw, Physical and Computational Aspects of Convective Heat Transfer, Springer-Verlag (1984). 


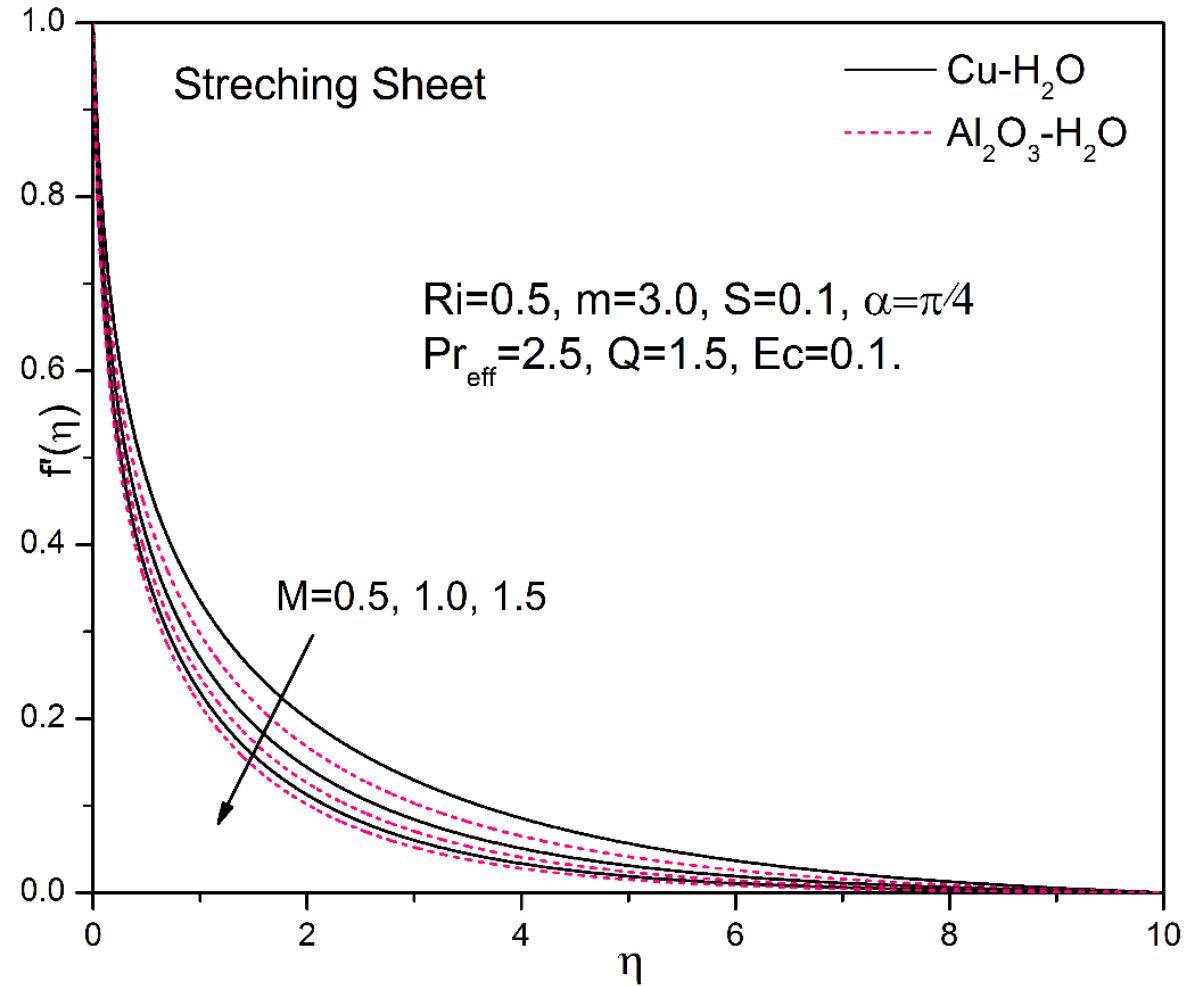

Fig. 3. The dimension less velocity profiles for different values of $M$ for stretching sheet.

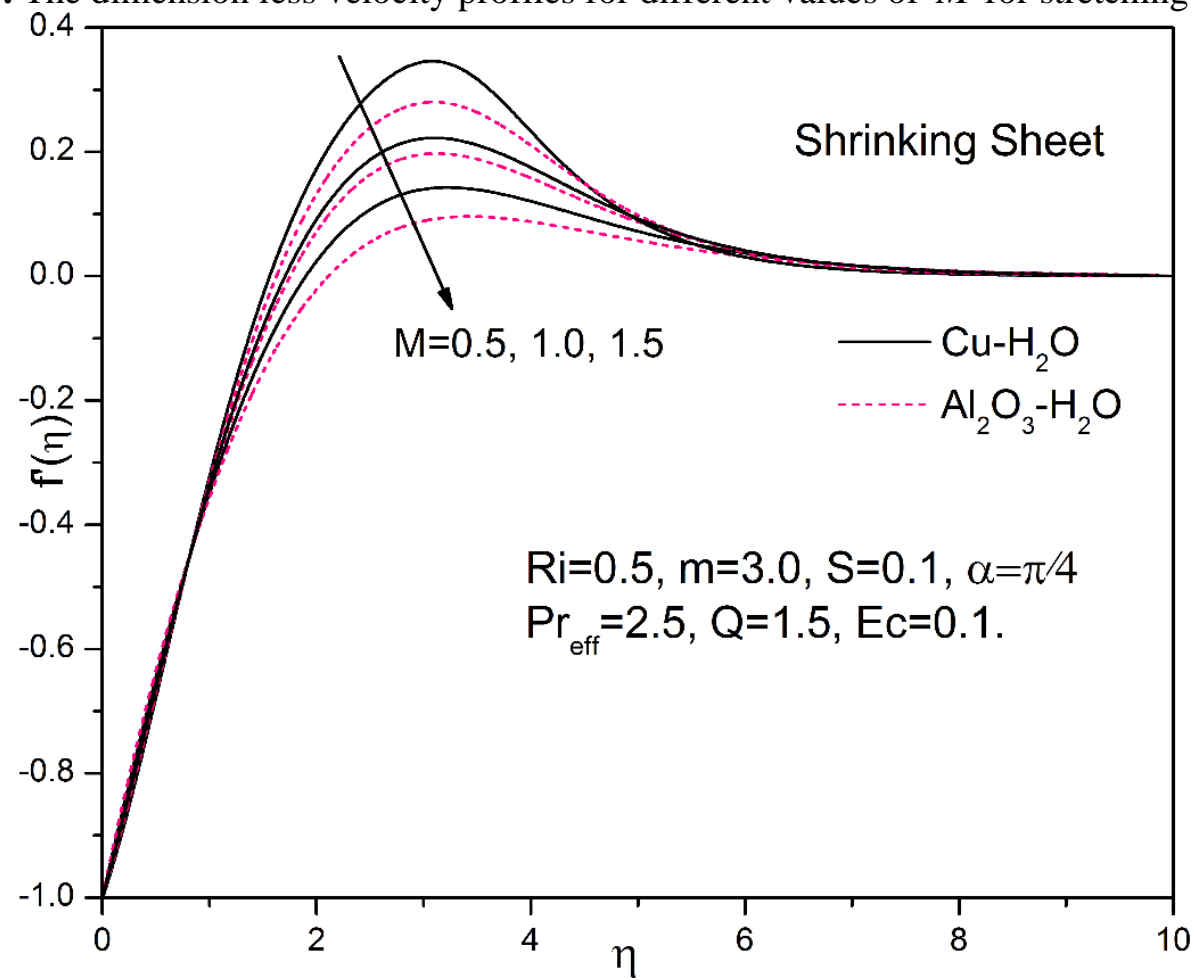

Fig. 4. The dimension less velocity profiles for different values of $M$ for stretching sheet. 


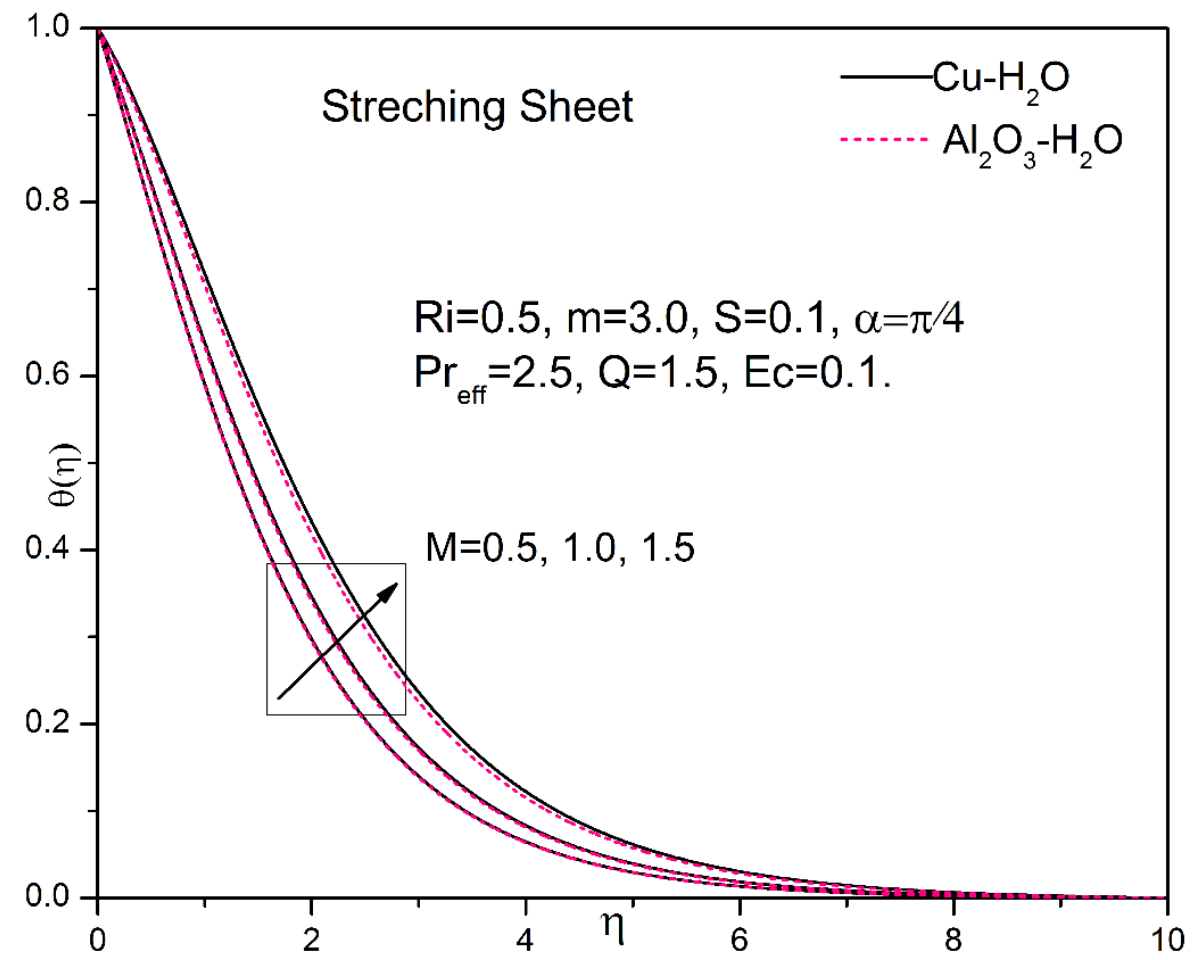

Fig. 5. The dimension less temperature profiles for different values of $M$ for stretching sheet.

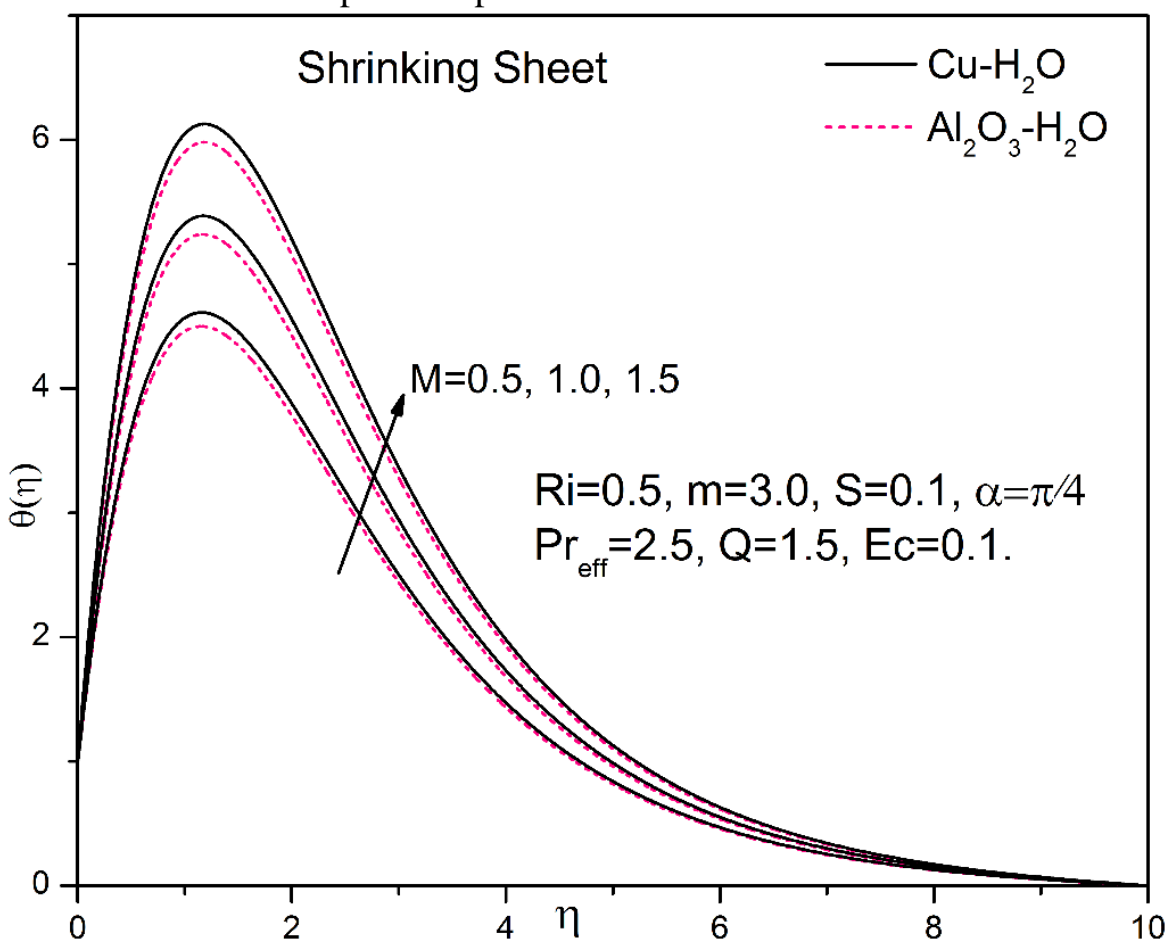

Fig. 6. The dimension less temperature profiles for different values of $M$ for shrinking sheet. 


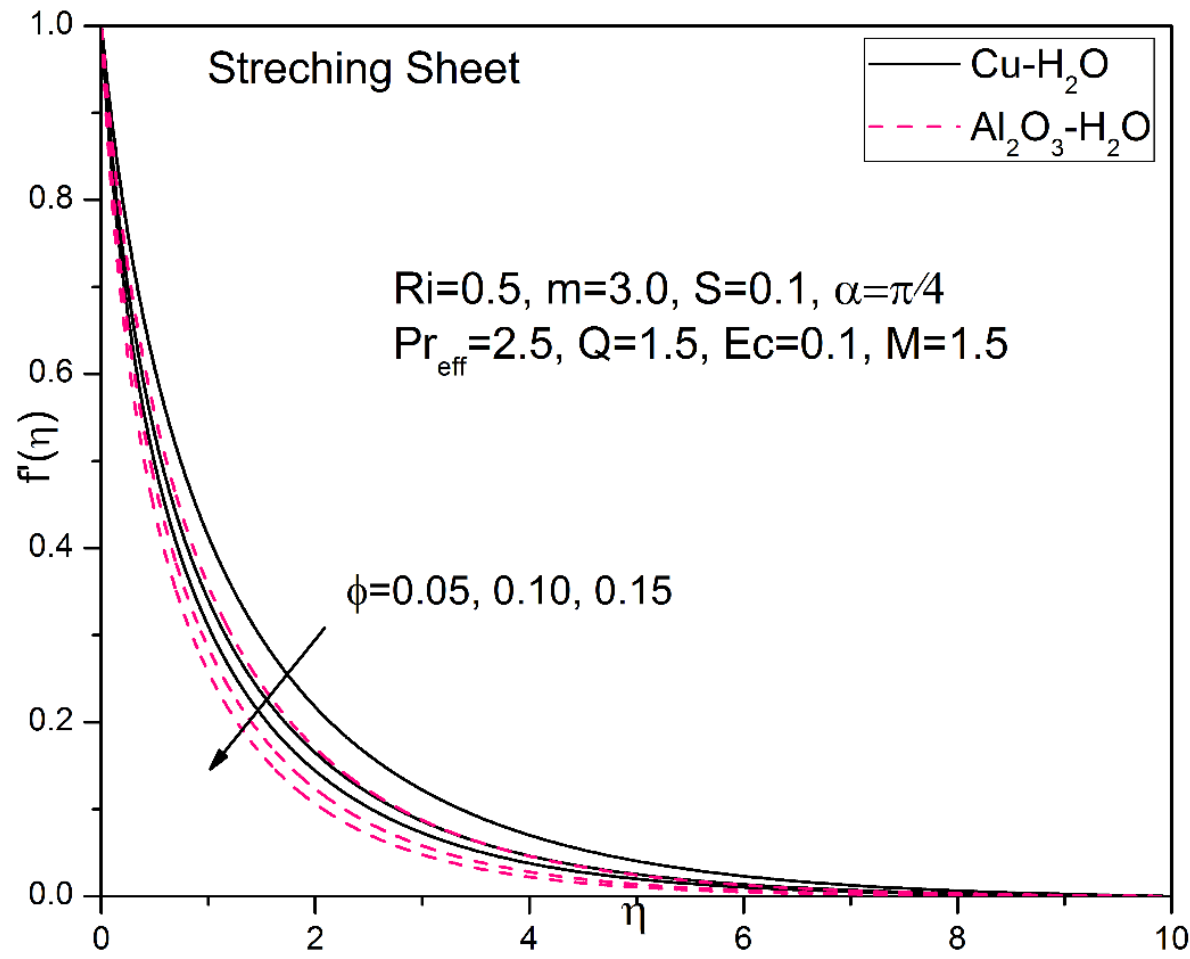

Fig. 7. The dimension less velocity profiles for different values of $\phi$ for stretching sheet.

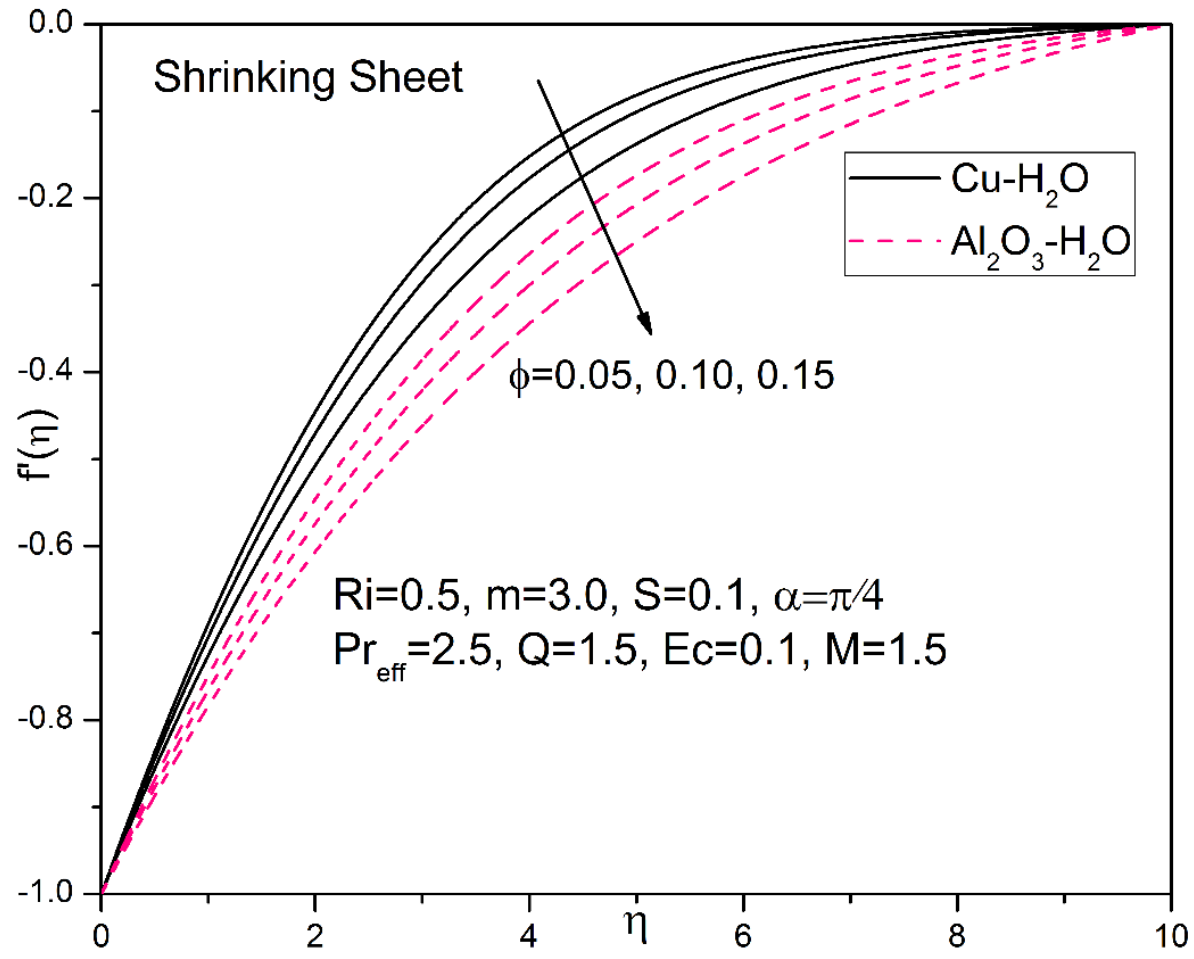

Fig. 8. The dimension less velocity profiles for different values of $\phi$ for stretching sheet. 


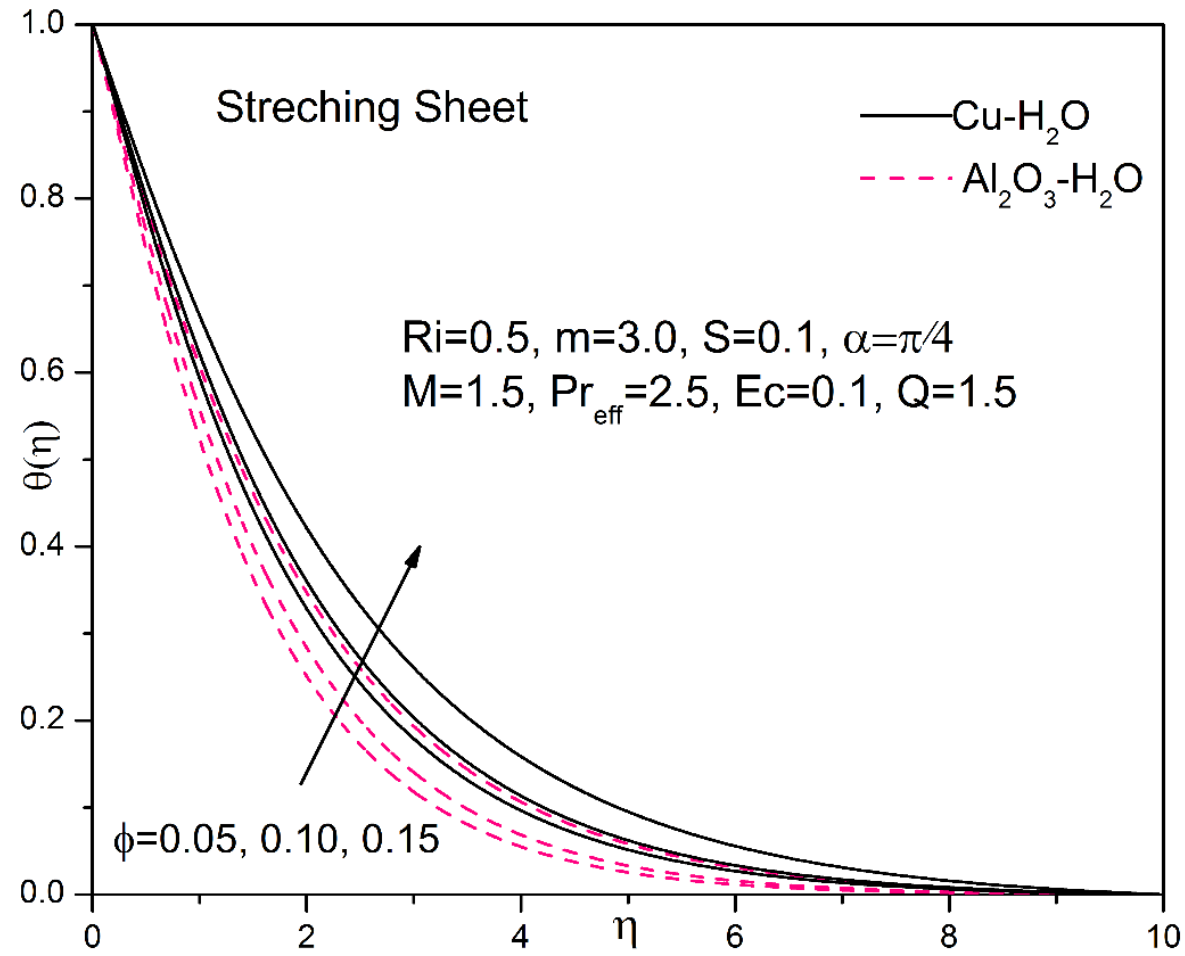

Fig. 9. The dimension less temperature profiles for different values of $\phi$ for stretching sheet.

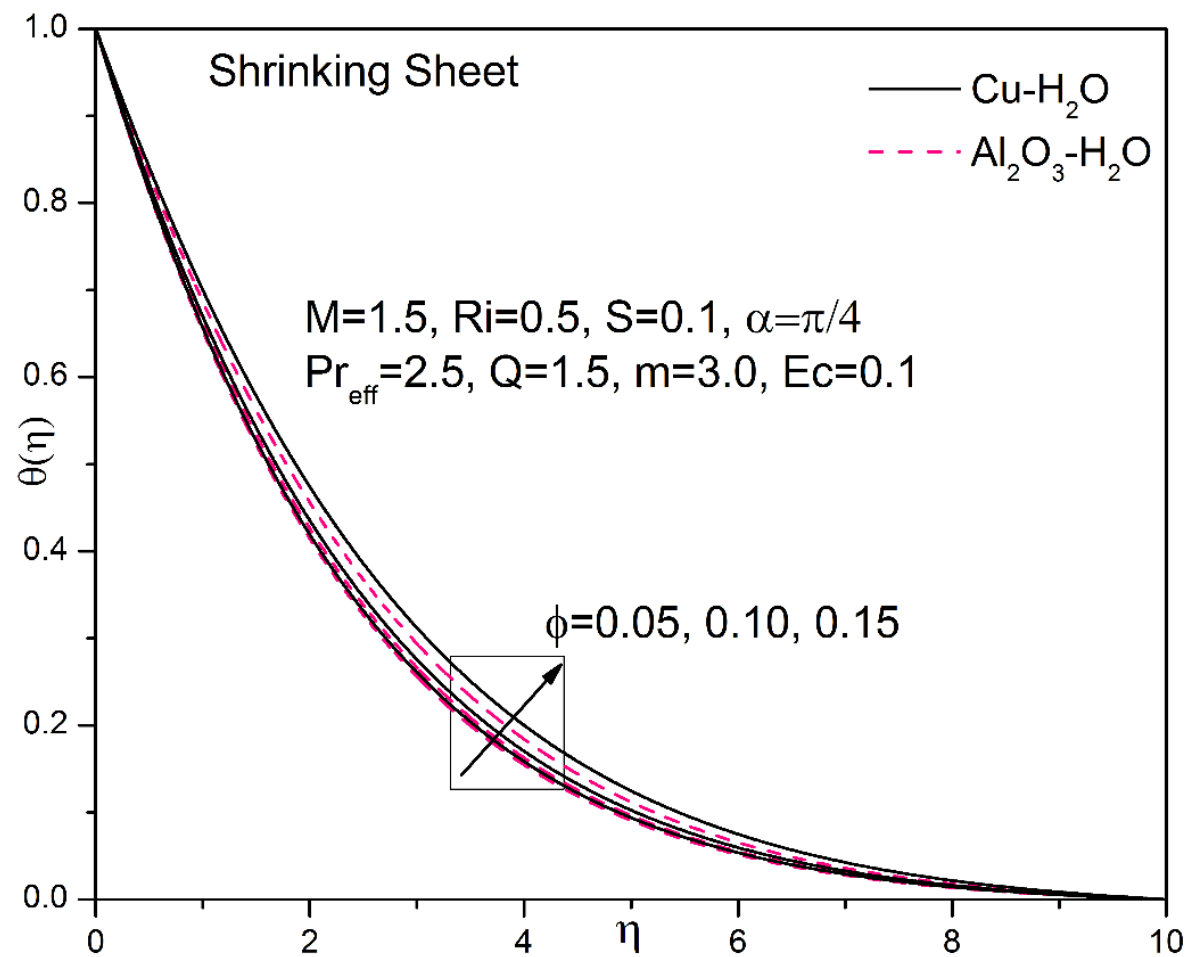

Fig. 10. The dimension less temperature profiles for different values of $\phi$ for shrinking sheet. 


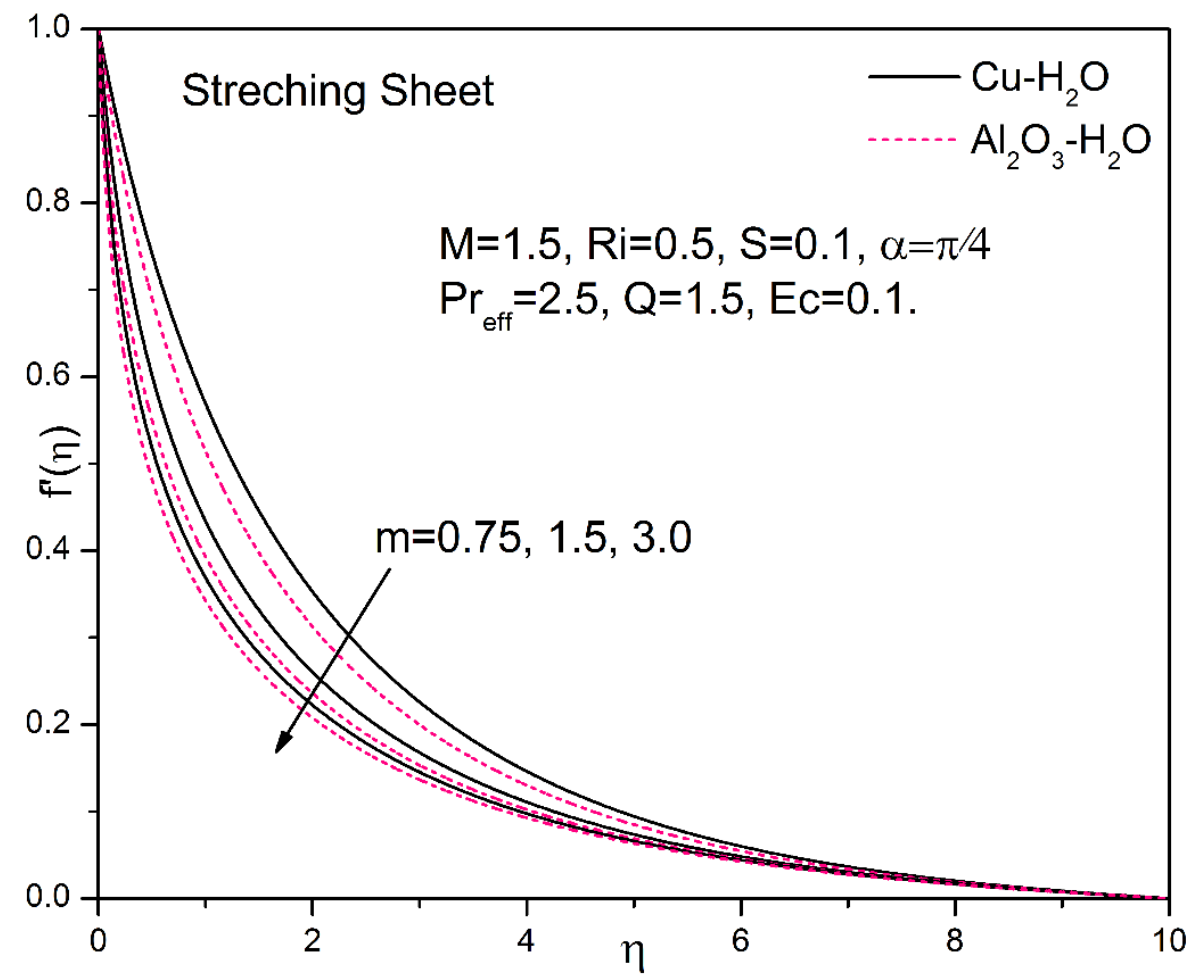

Fig. 11. The dimension less velocity profiles for different values of $m$ for stretching sheet.

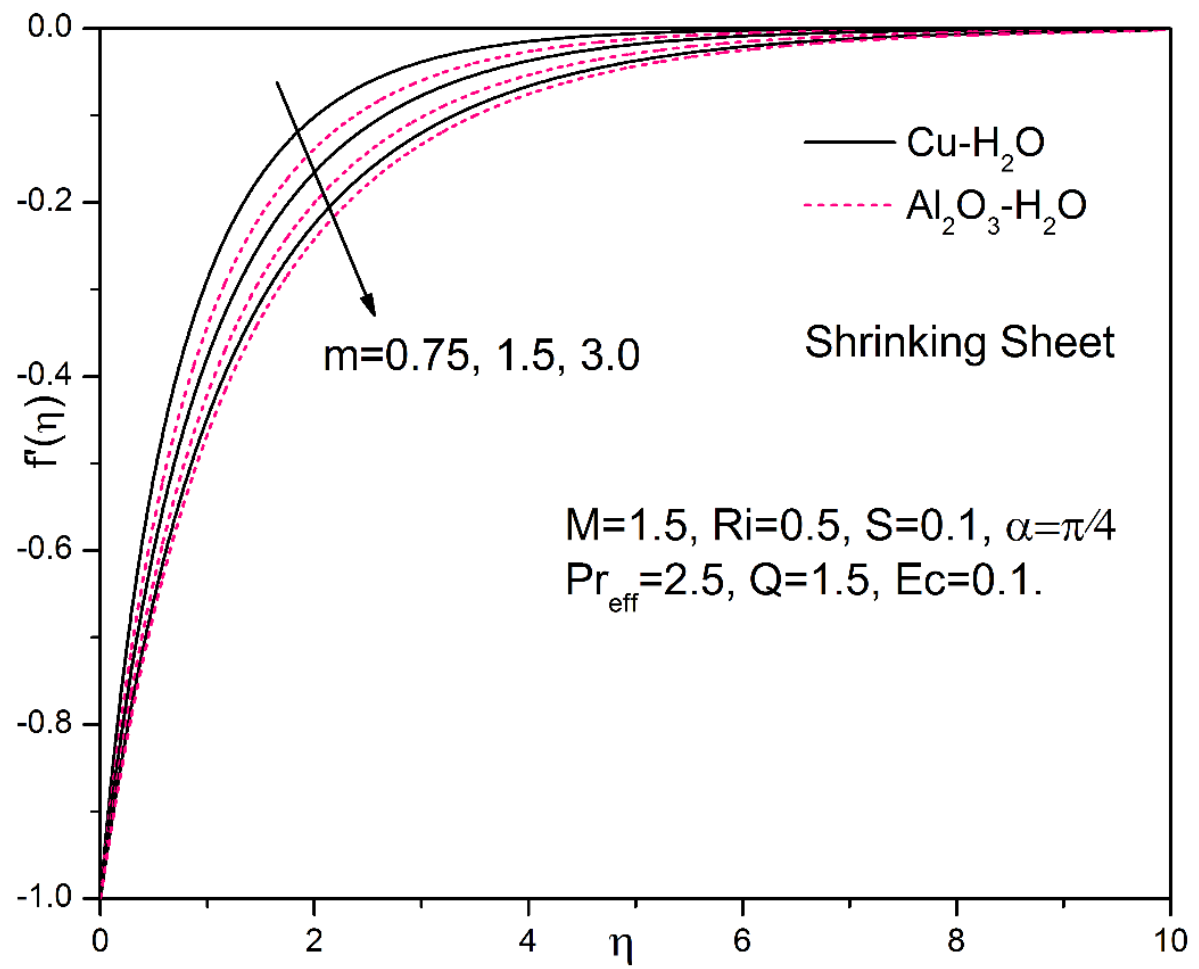

Fig. 12. The dimension less velocity profiles for different values of $m$ for stretching sheet. 


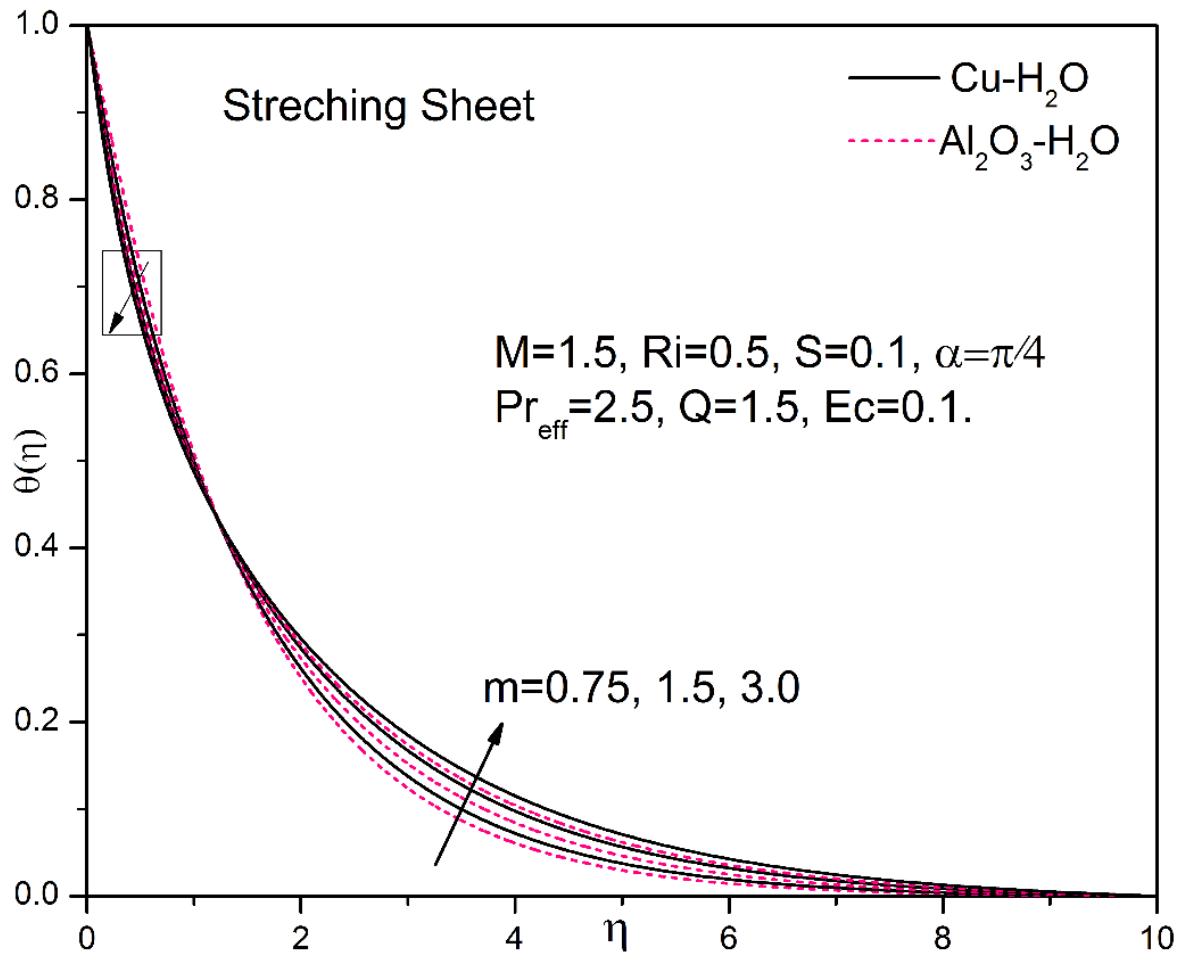

Fig. 13. The dimension less temperature profiles for different values of $m$ for stretching sheet.

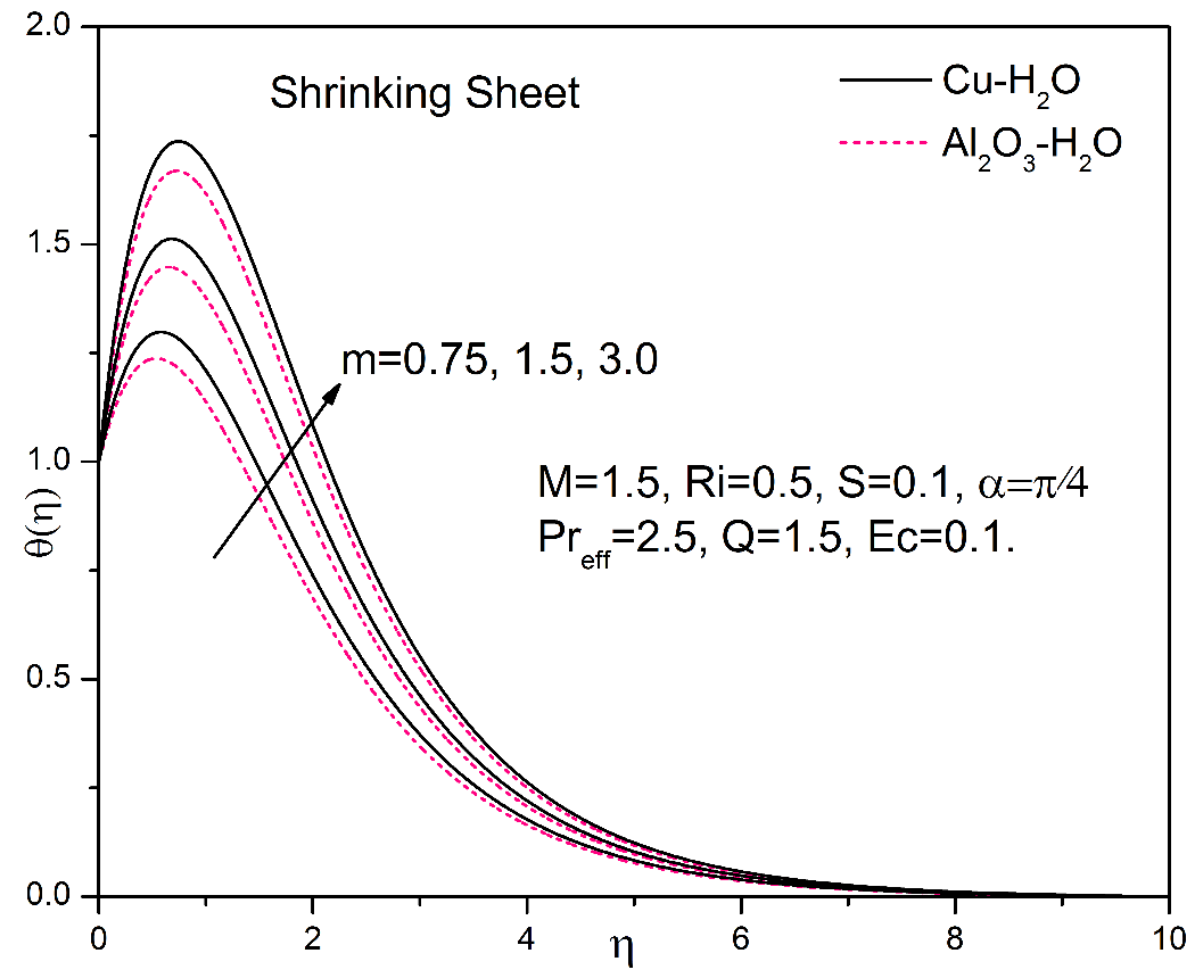

Fig. 14. The dimension less temperature profiles for different values of $m$ for shrinking sheet. 


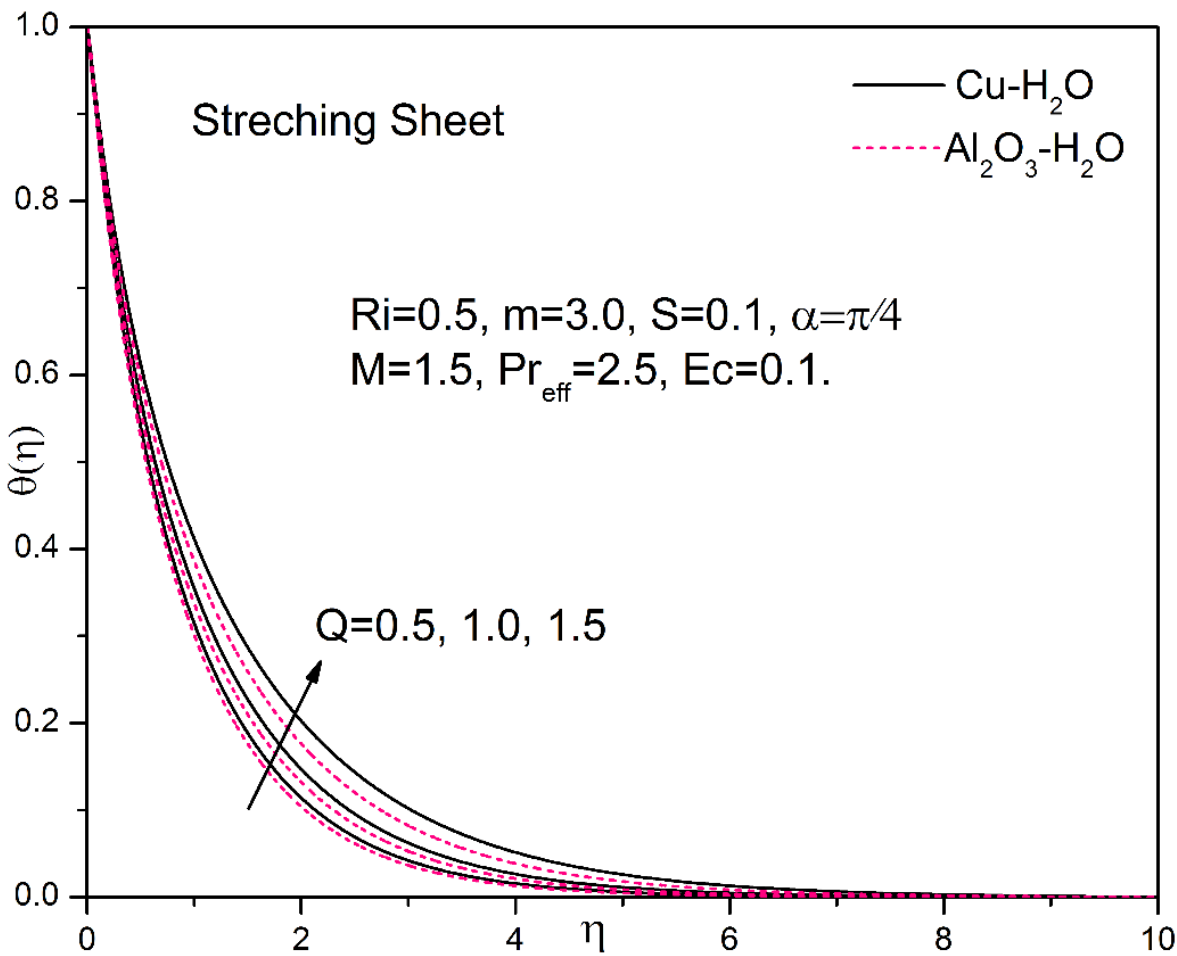

Fig. 15. The dimension less temperature profiles for different values of $Q$ for stretching sheet.

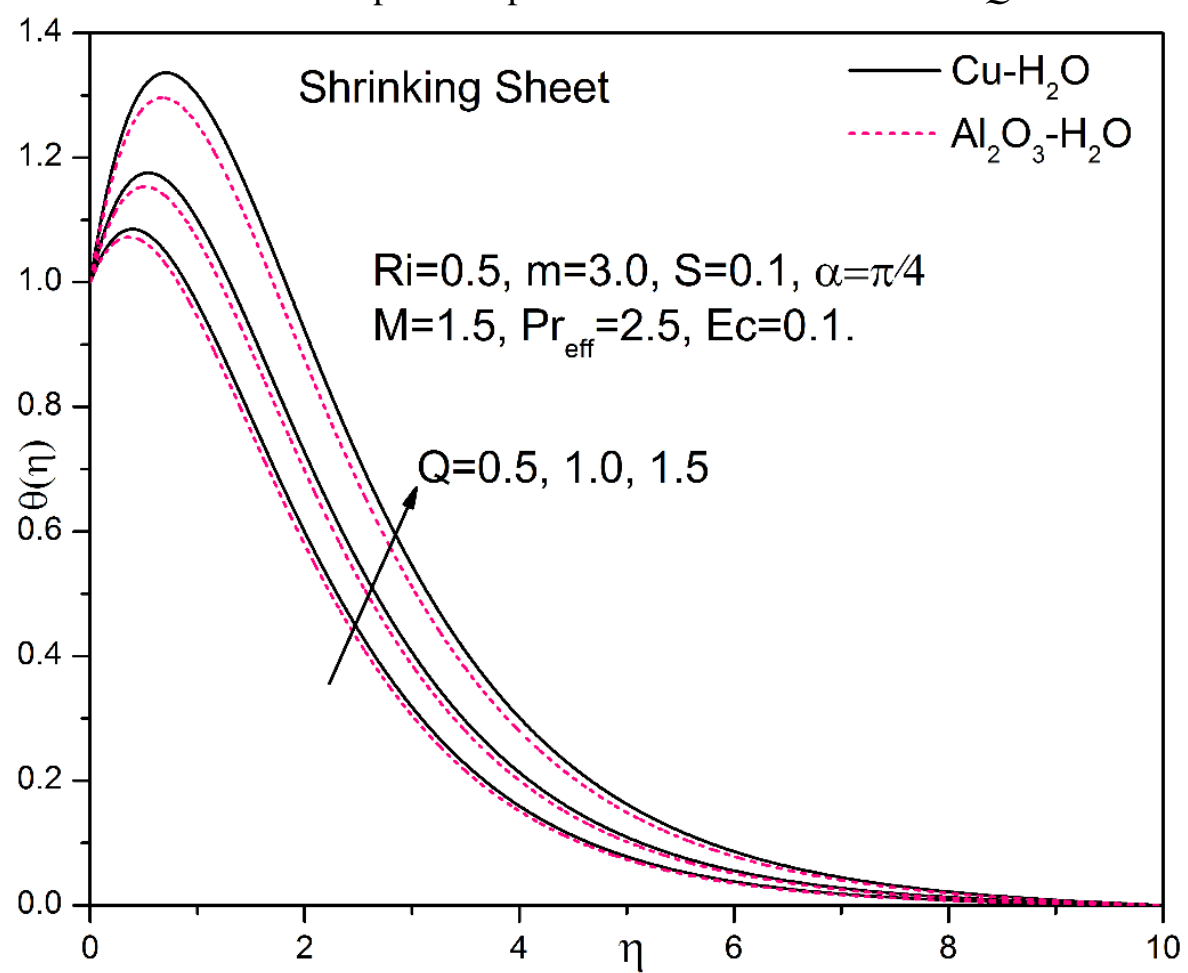

Fig. 16. The dimension less temperature profiles for different values of $Q$ for shrinking sheet. 


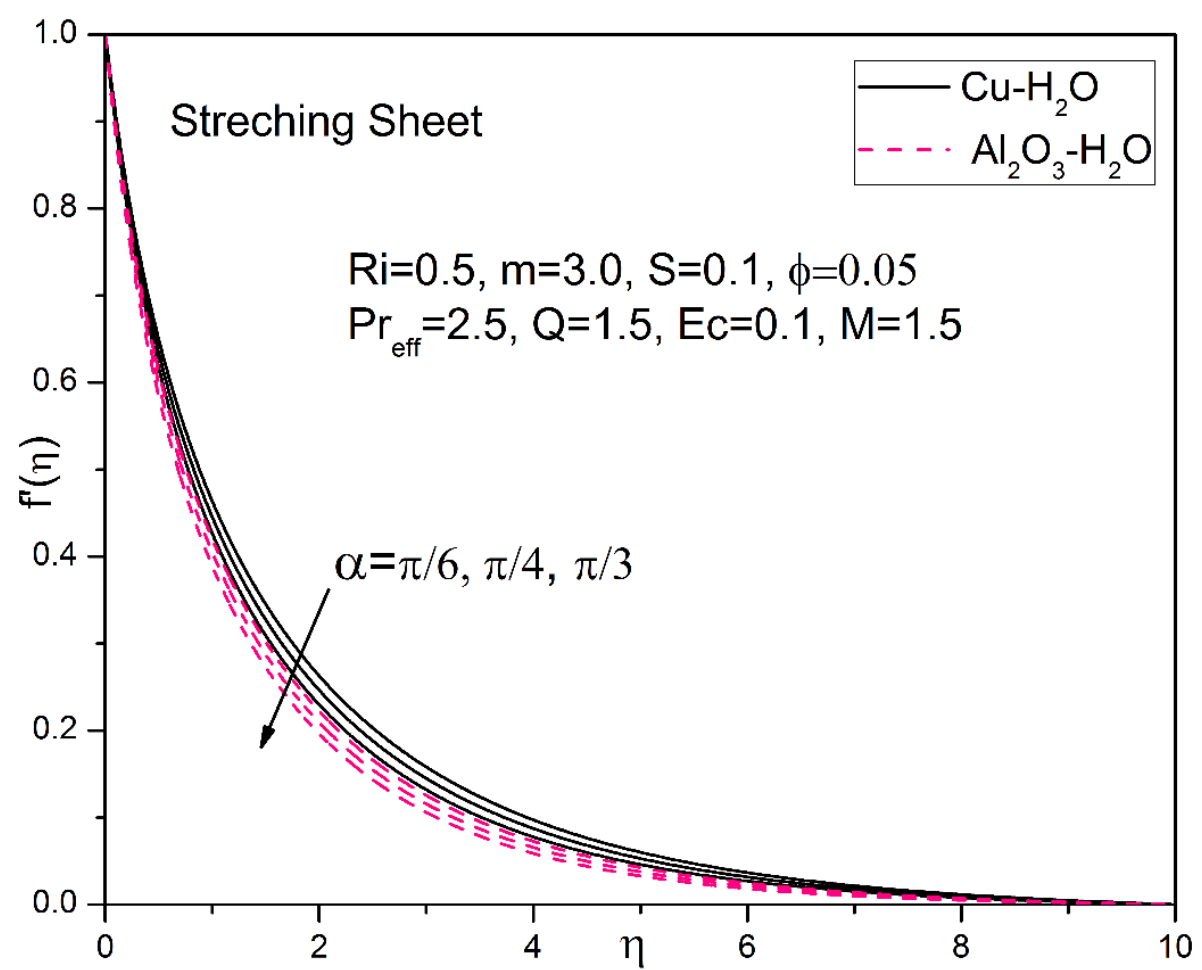

Fig. 17. The dimension less velocity profiles for different values of $\alpha$ for stretching sheet.

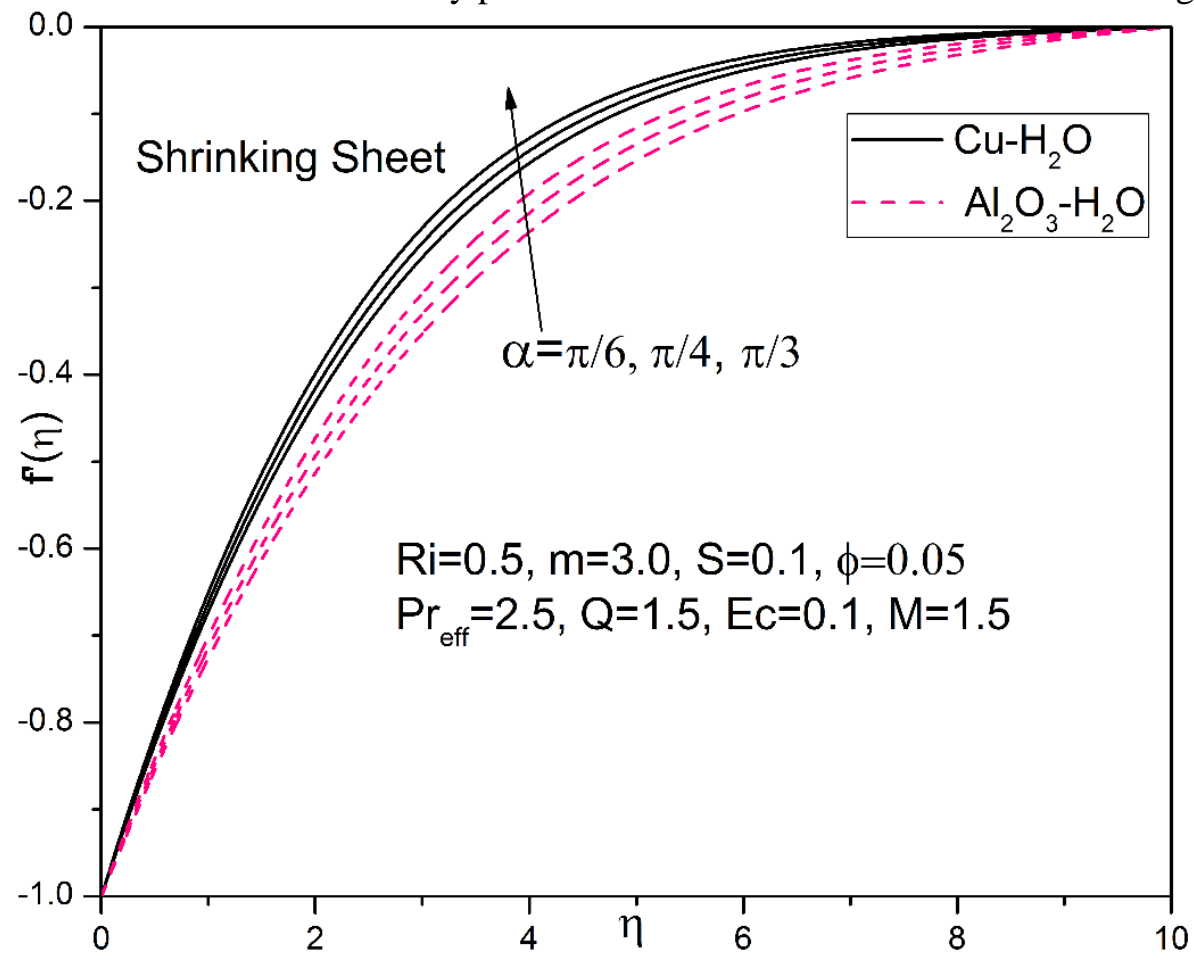

Fig. 18. The dimension less velocity profiles for different values of $\alpha$ for shrinking sheet. 


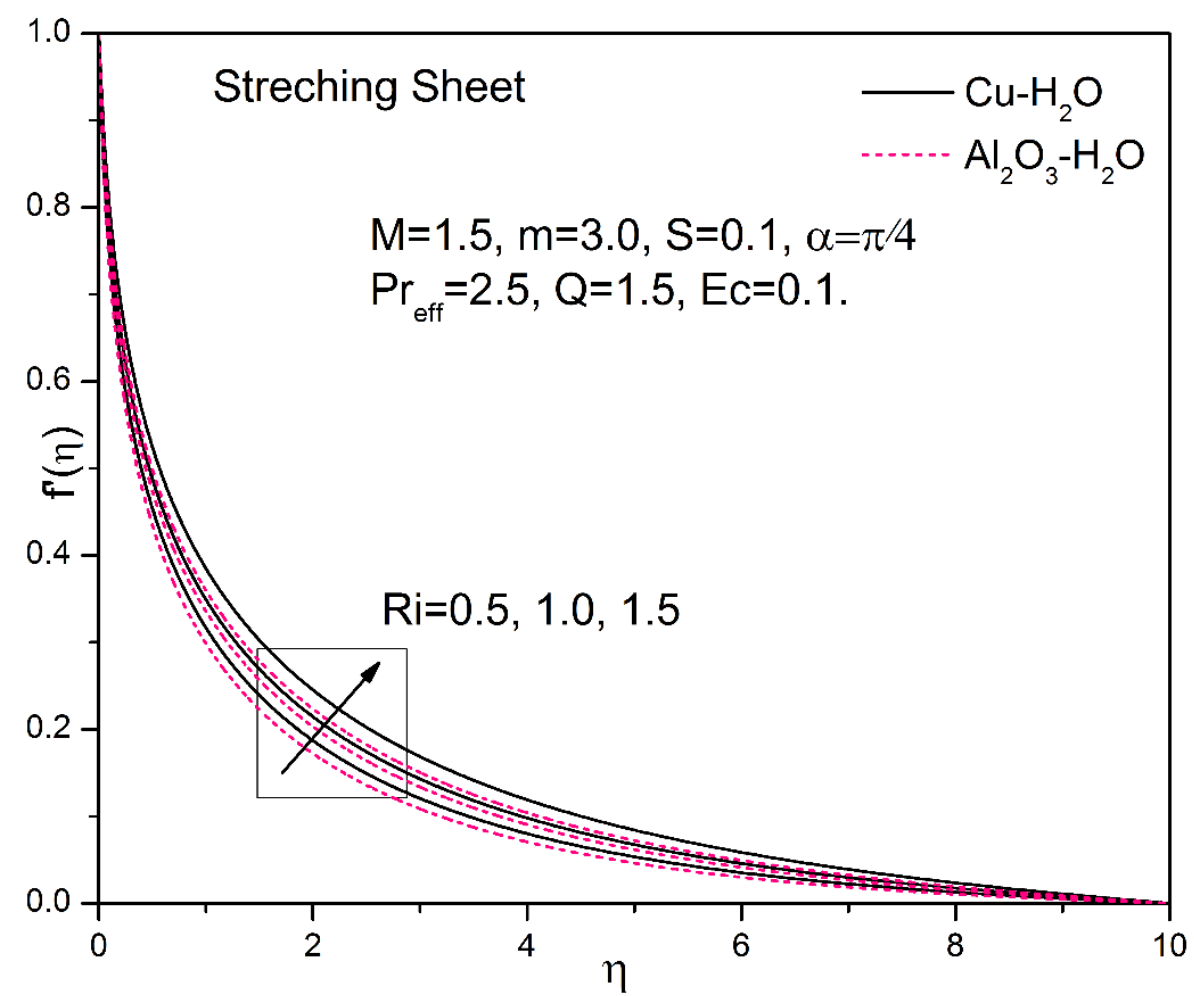

Fig. 19. The dimension less velocity profiles for different values of $R i$ for stretching sheet.

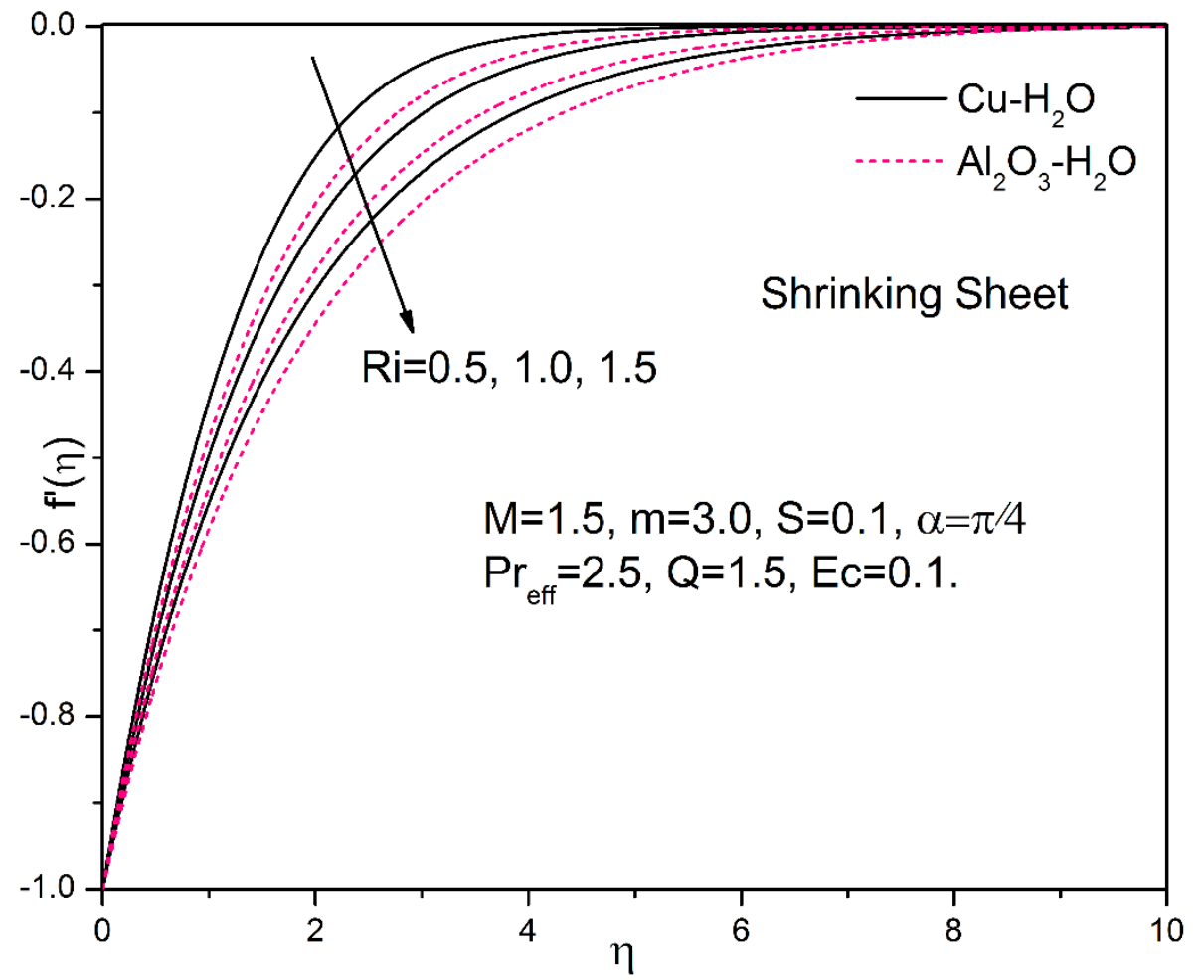

Fig. 20. The dimension less velocity profiles for different values of $R i$ for shrinking sheet. 


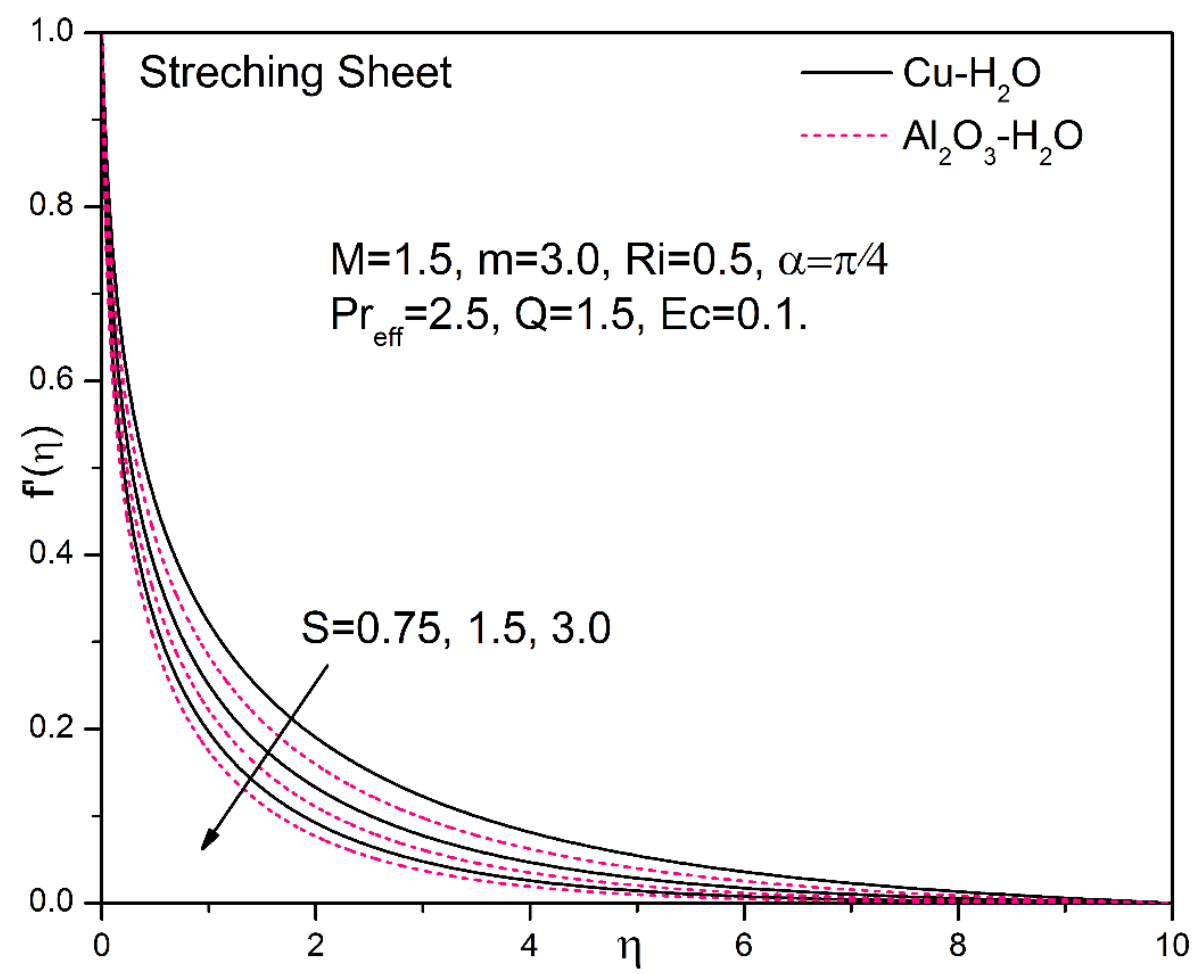

Fig. 21. The dimension less velocity profiles for different values of $S$ for stretching sheet.

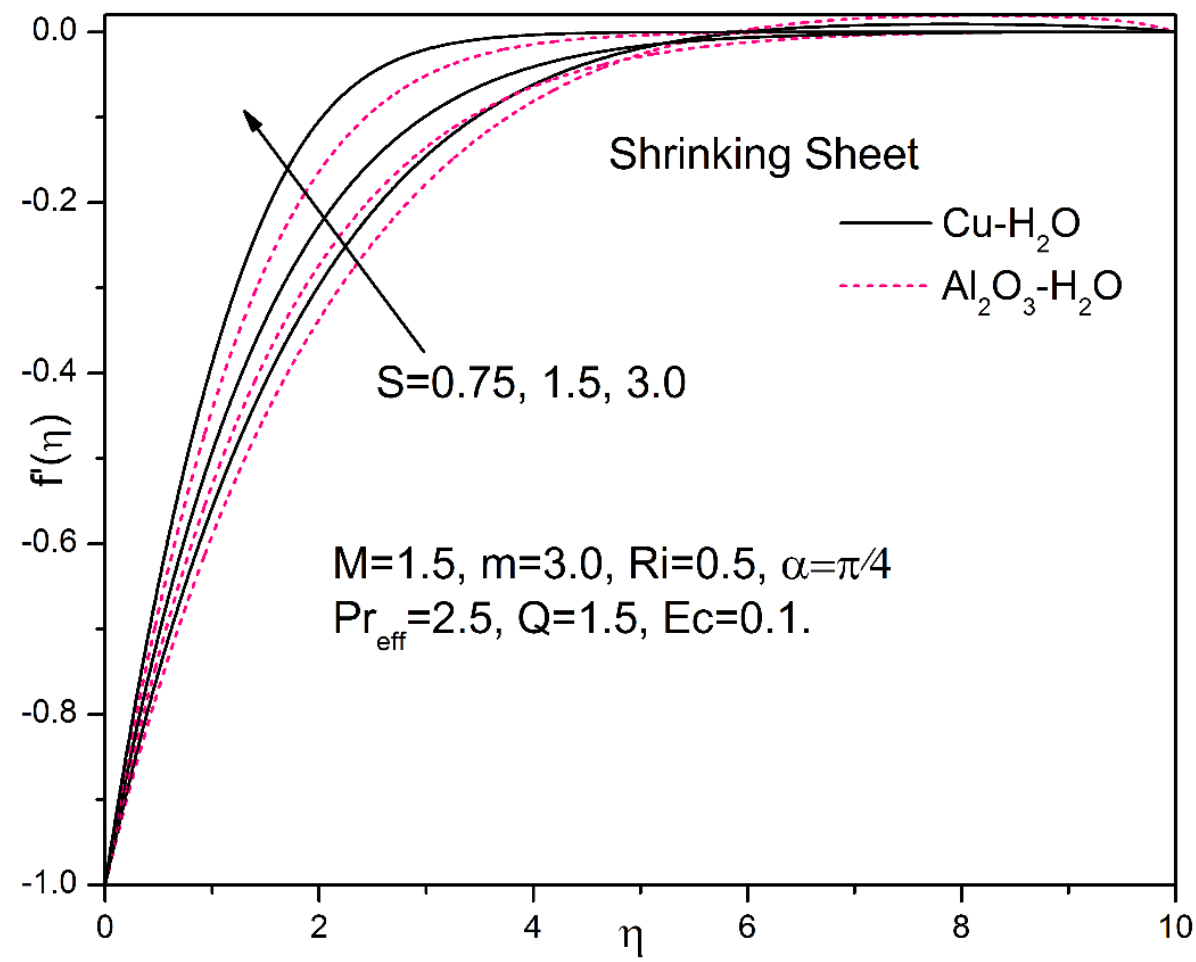

Fig. 22. The dimension less velocity profiles for different values of $S$ for shrinking sheet. 


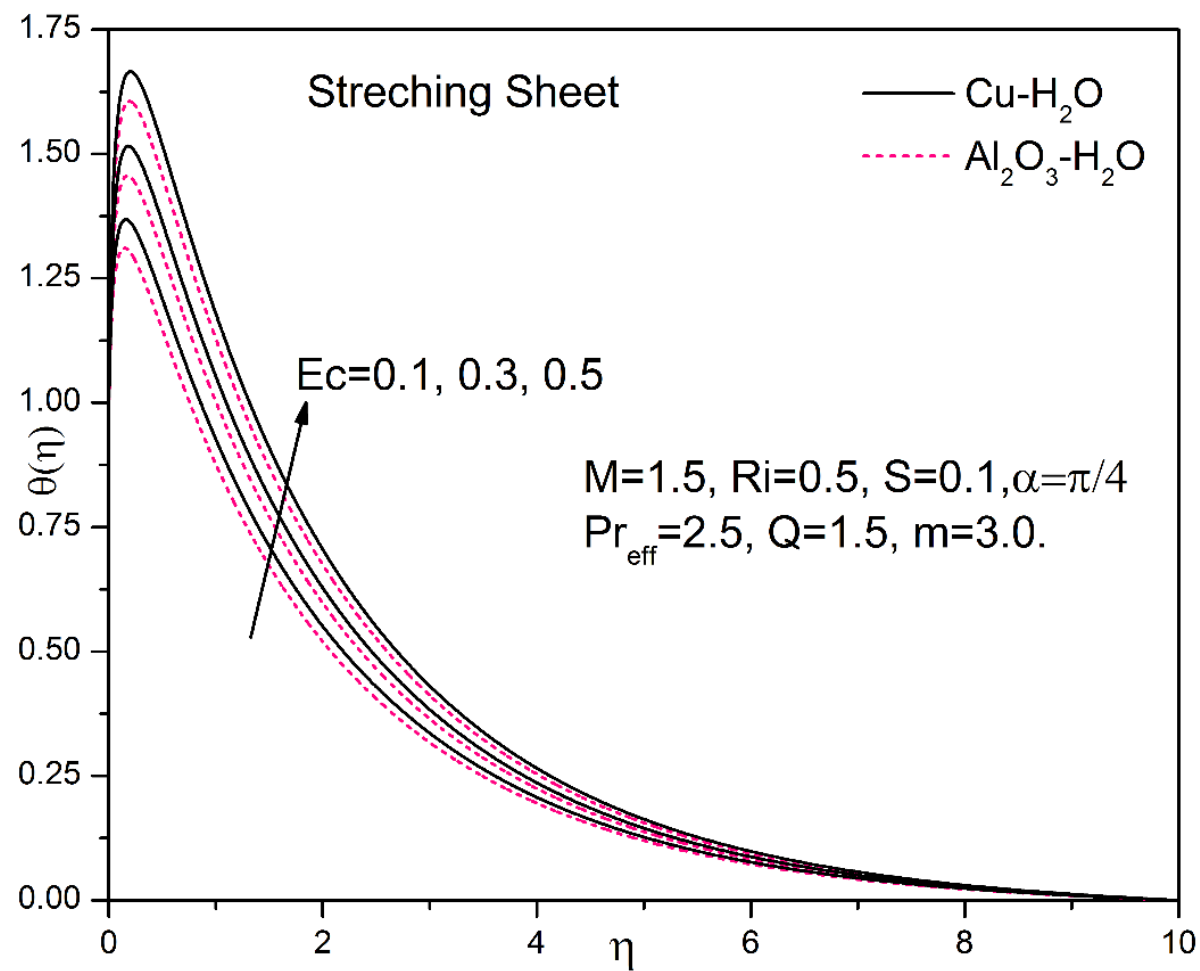

Fig. 23. The dimension less temperature profiles for different values of $E c$ for stretching sheet.

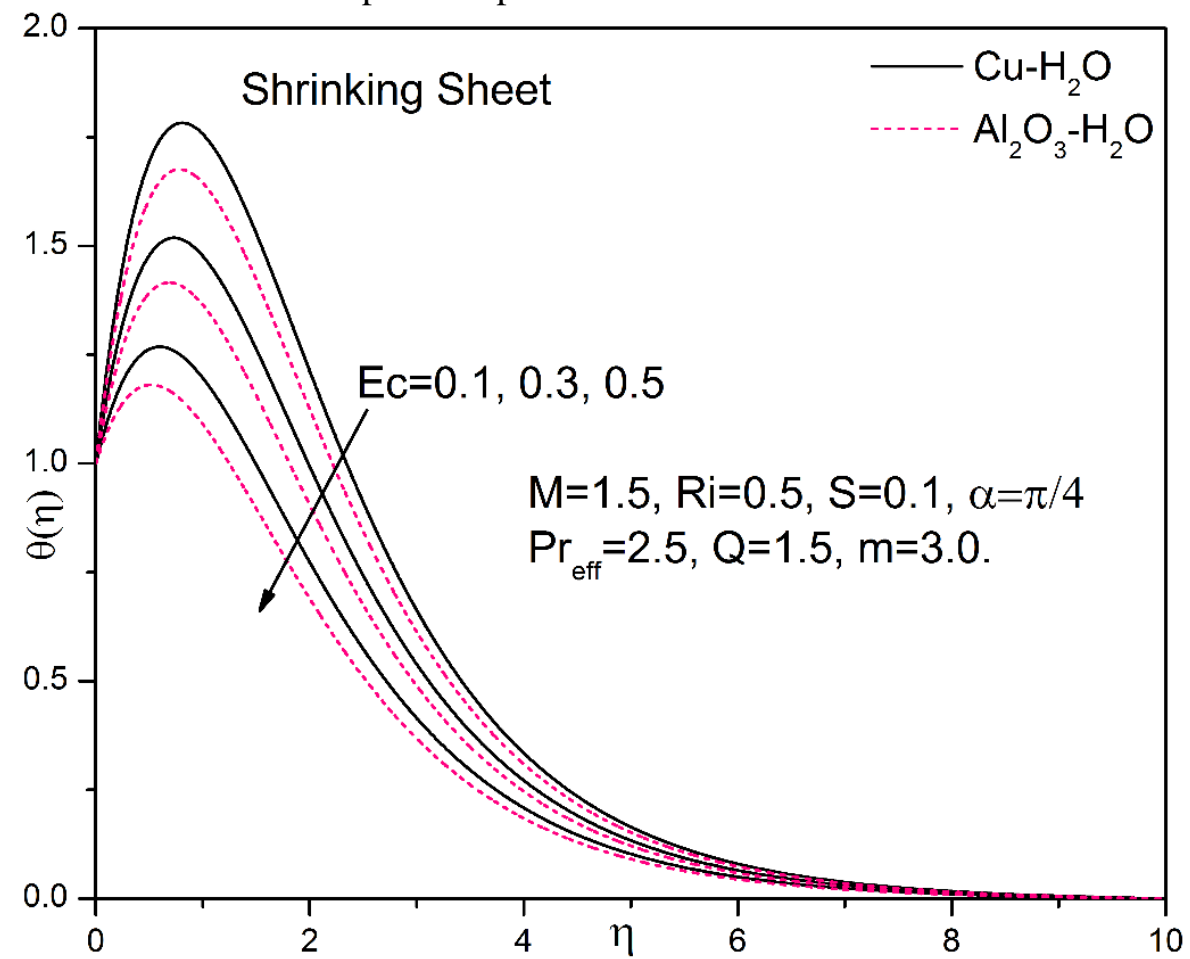

Fig. 24. The dimension less temperature profiles for different values of $E c$ for shrinking sheet. 


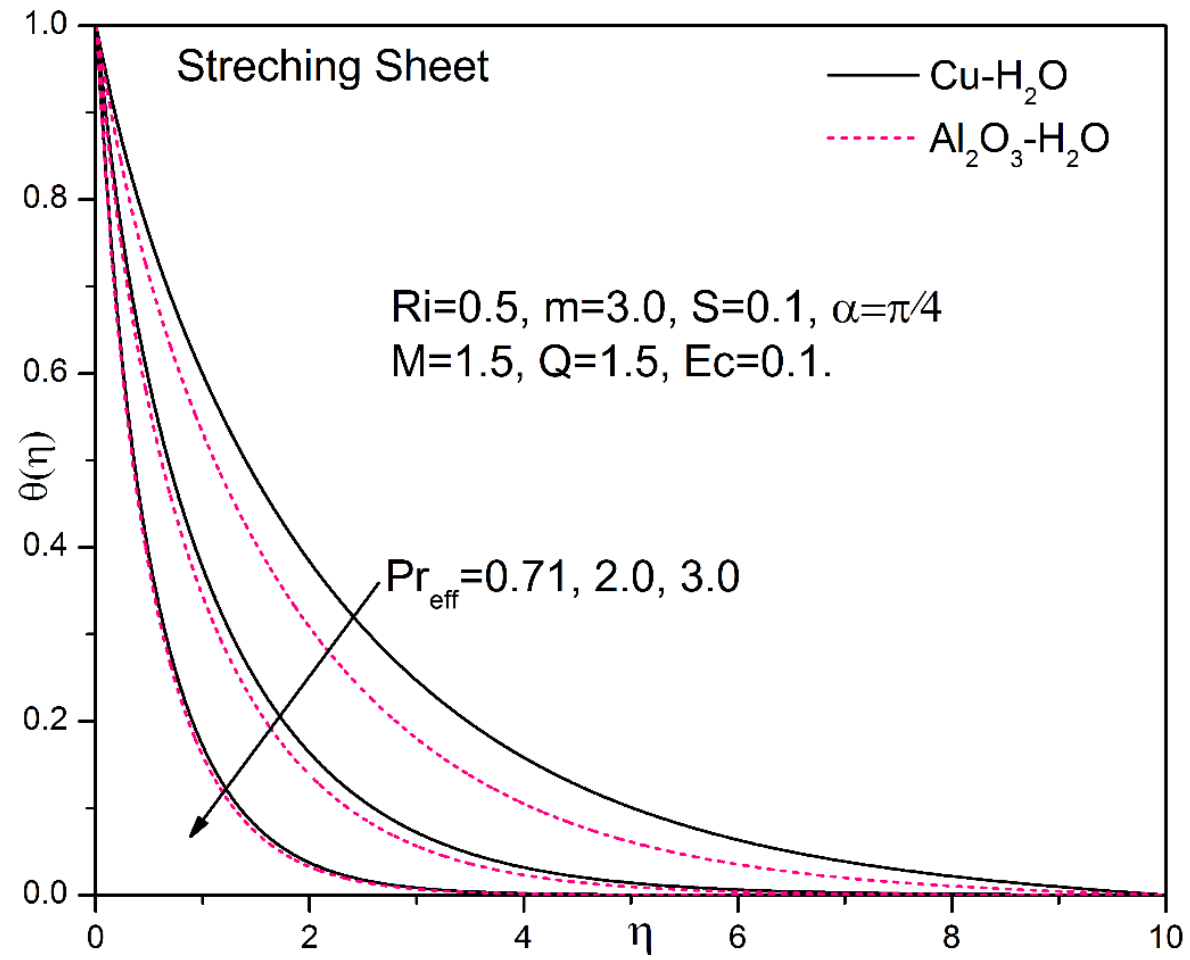

Fig. 25. The dimension less temperature profiles for different values of $\operatorname{Pr}_{\text {eff }}$ for stretching sheet.

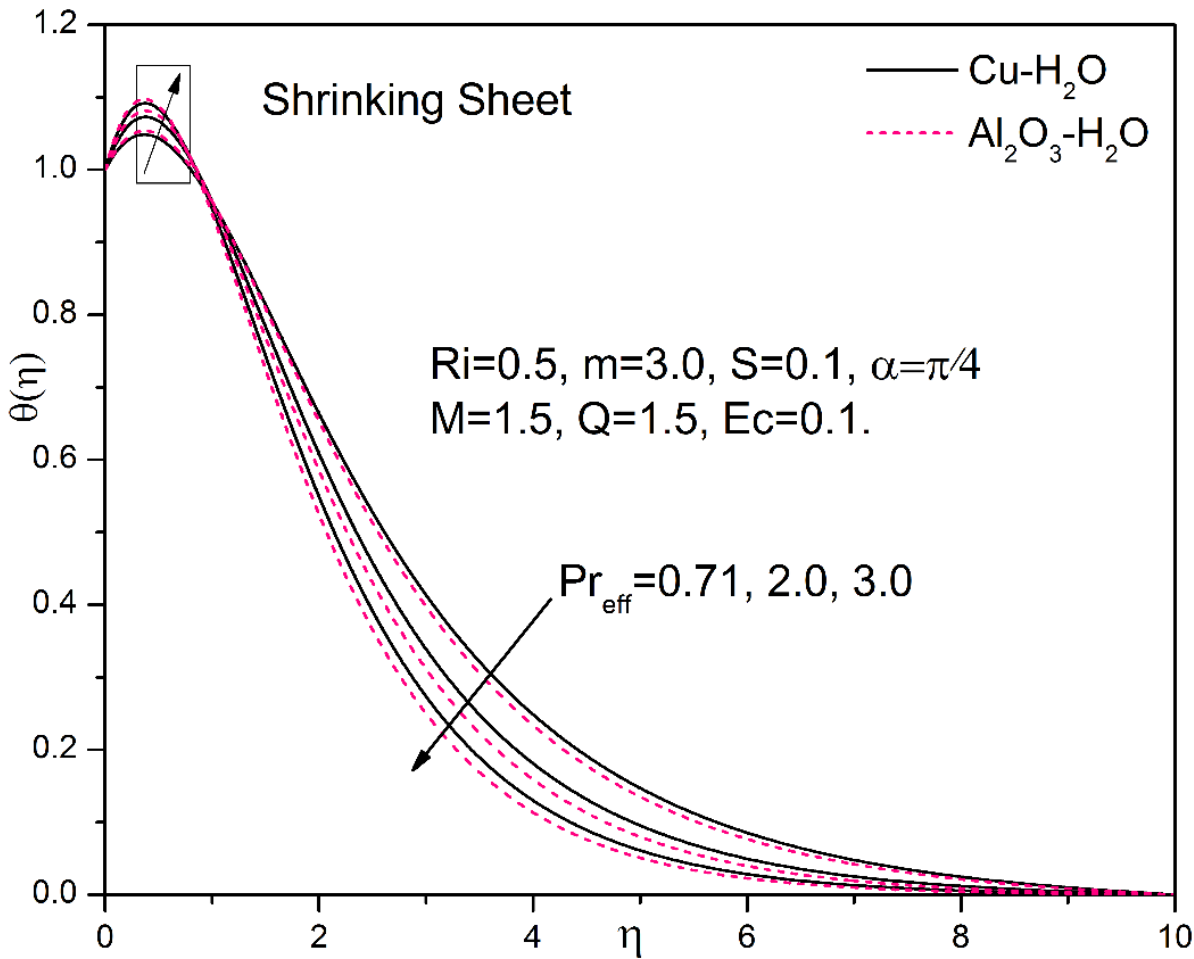

Fig. 26. The dimension less temperature profiles for different values of $\operatorname{Pr}_{\text {eff }}$ for shrinking sheet. 


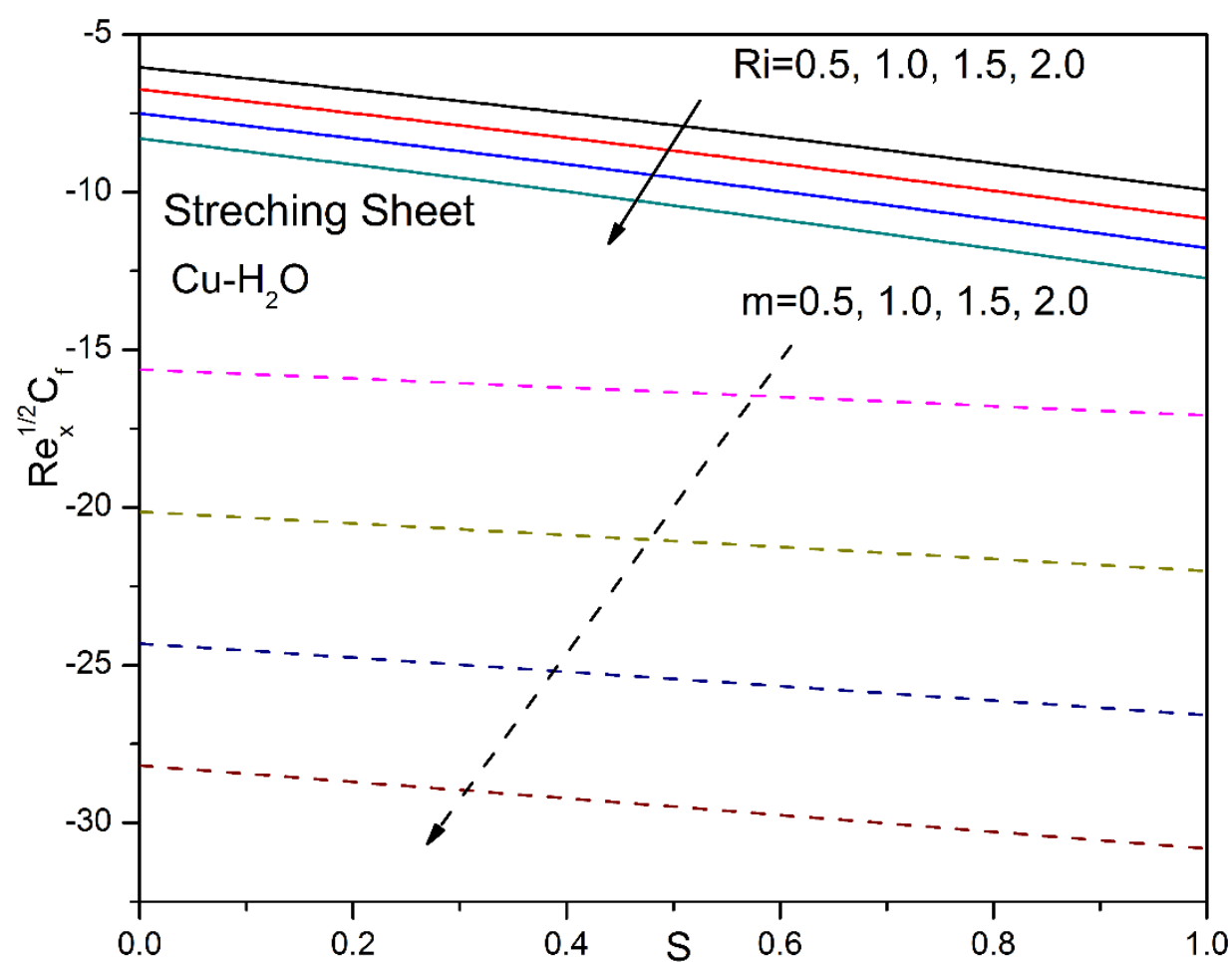

Fig. 27. Variation of the skin friction coefficient with Ri and $m$ for stretching sheet.

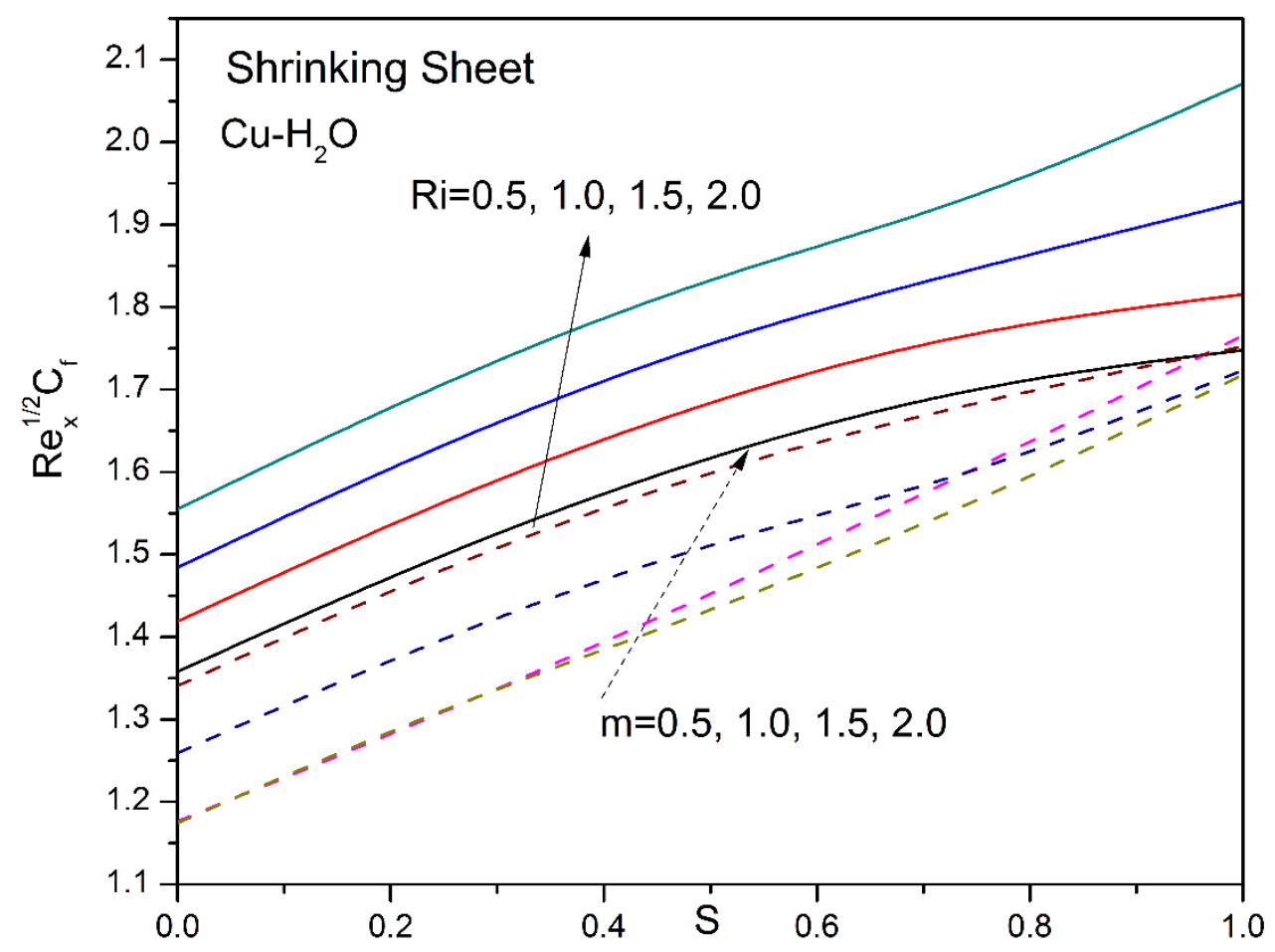

Fig. 28. Variation of the skin friction coefficient with Ri and $m$ for shrinking sheet. 


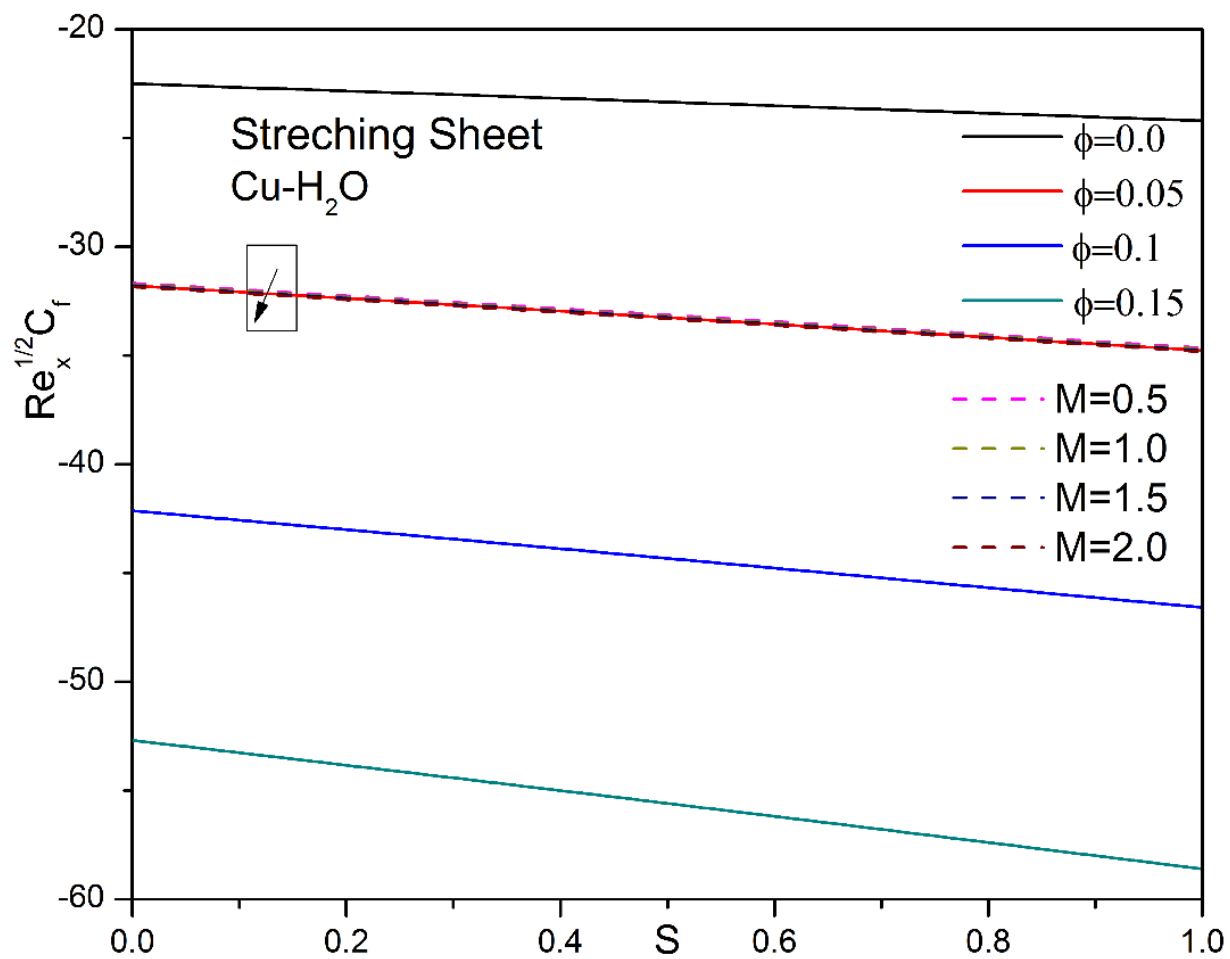

Fig. 29. Variation of the skin friction coefficient with $\phi$ and $M$ for stretching sheet.

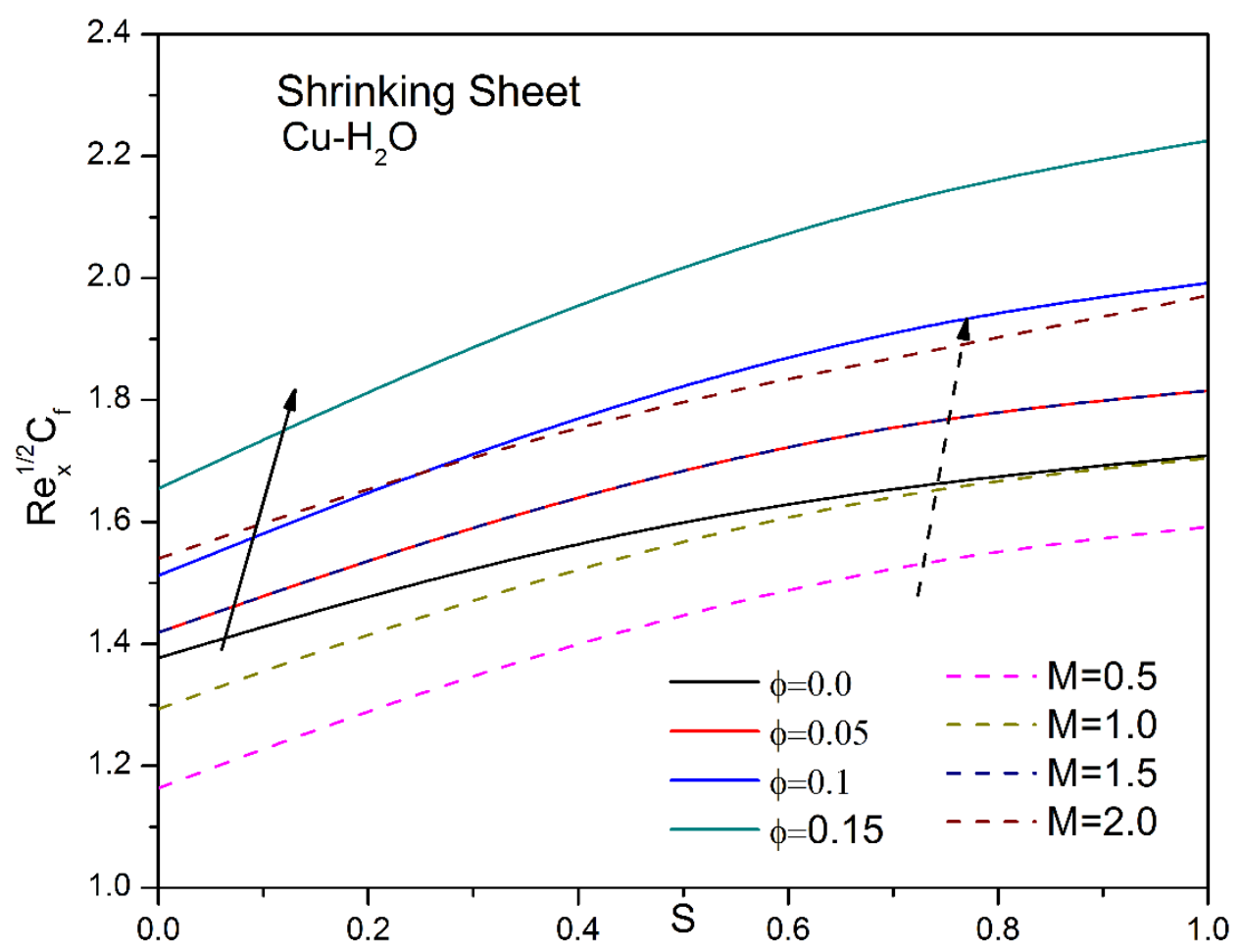

Fig. 30. Variation of the skin friction coefficient with $\phi$ and $M$ for shrinking sheet. 


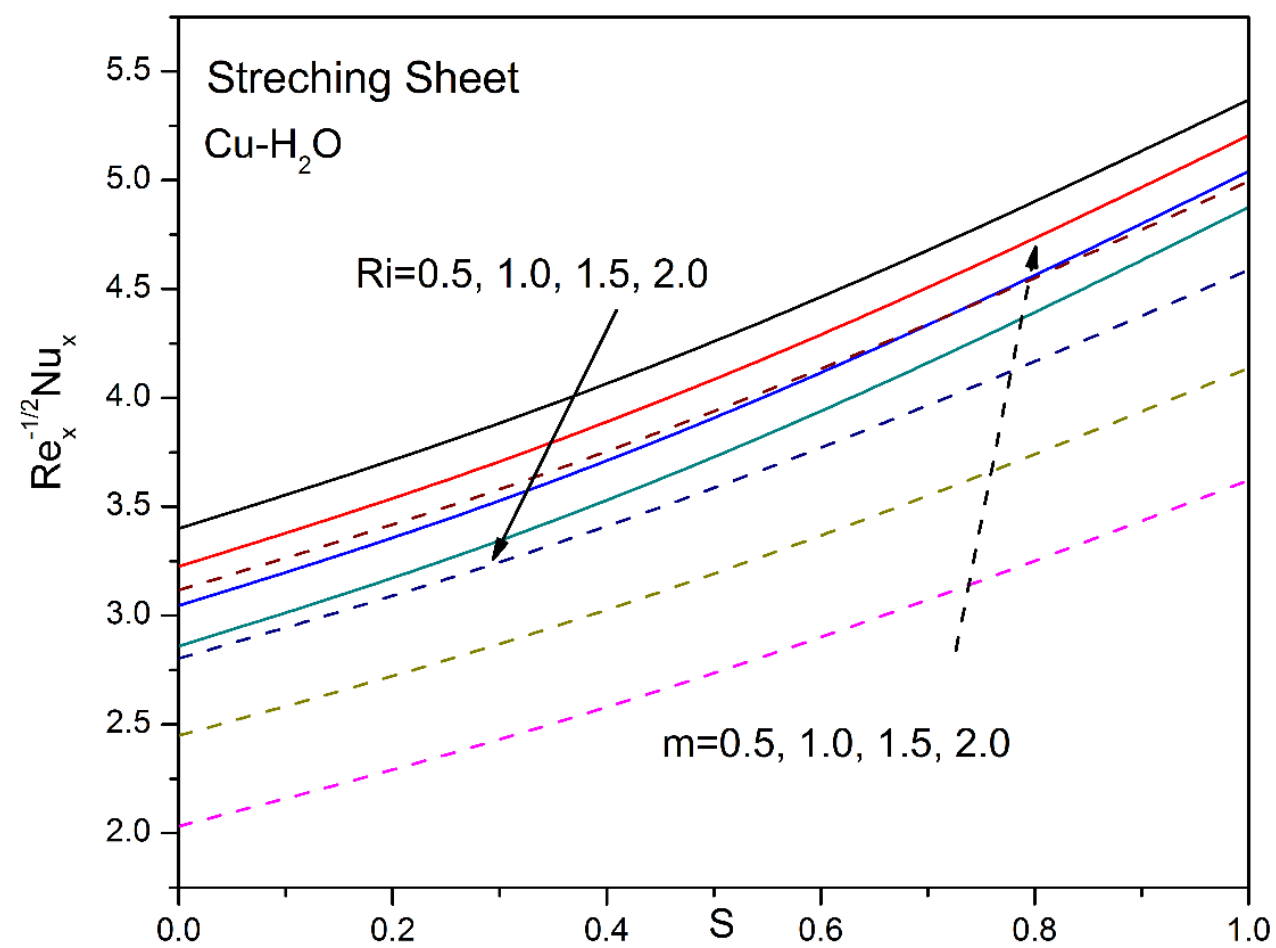

Fig. 31. Variation of the local Nusselt number with Ri and $m$ for stretching sheet.

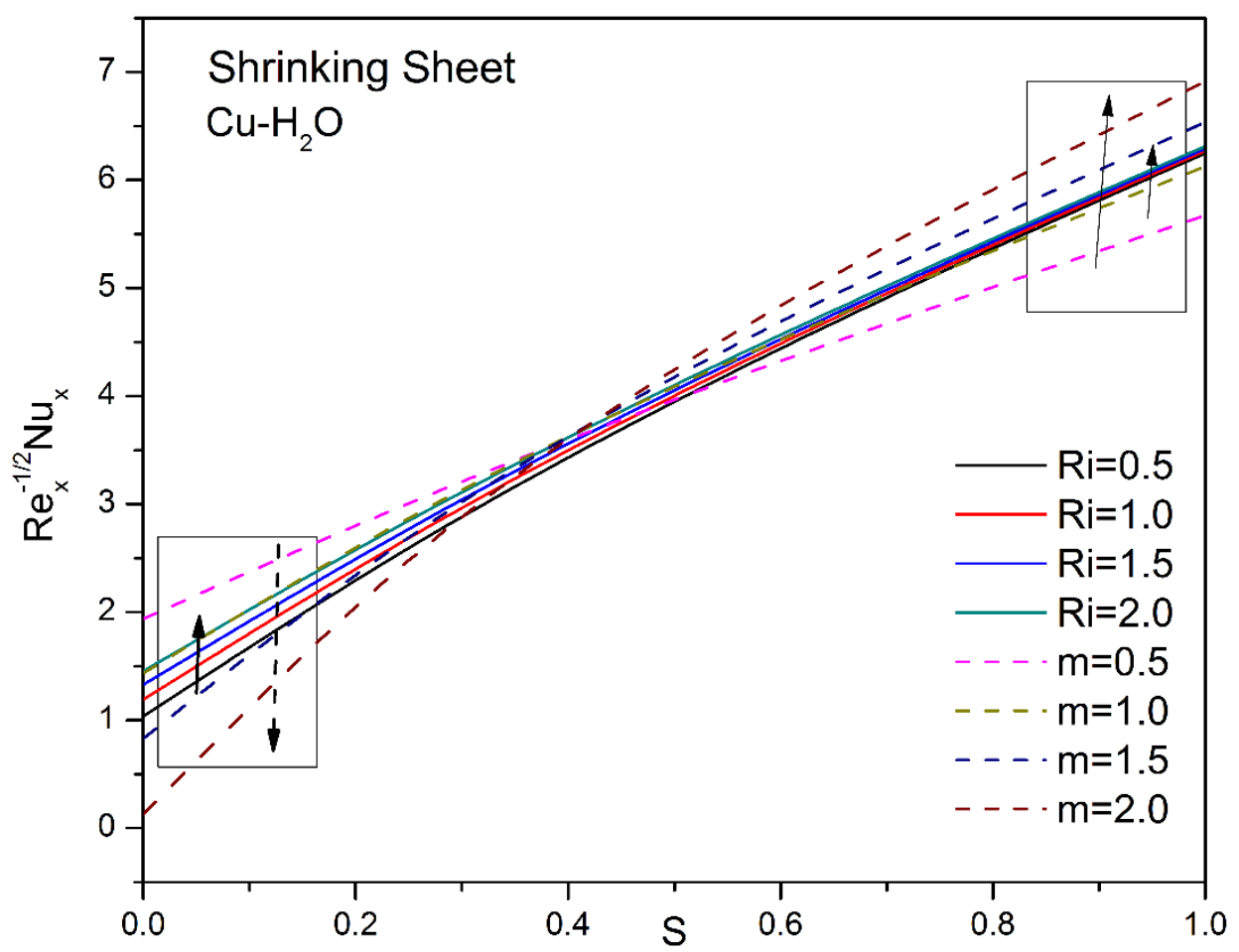

Fig. 32. Variation of the local Nusselt number with Ri and $m$ for shrinking sheet. 


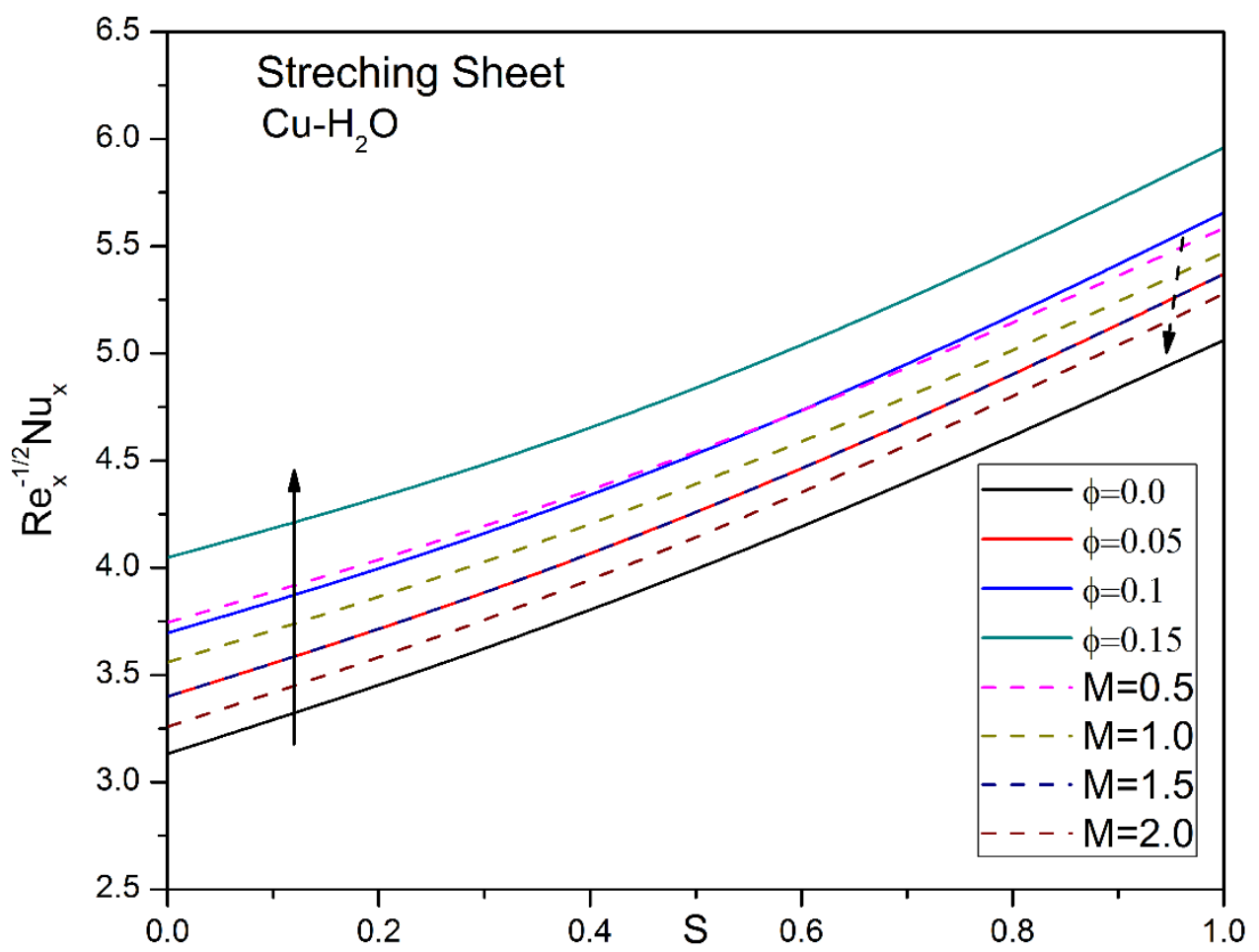

Fig. 33. Variation of the local Nusselt number with $\phi$ and $M$ for stretching sheet.

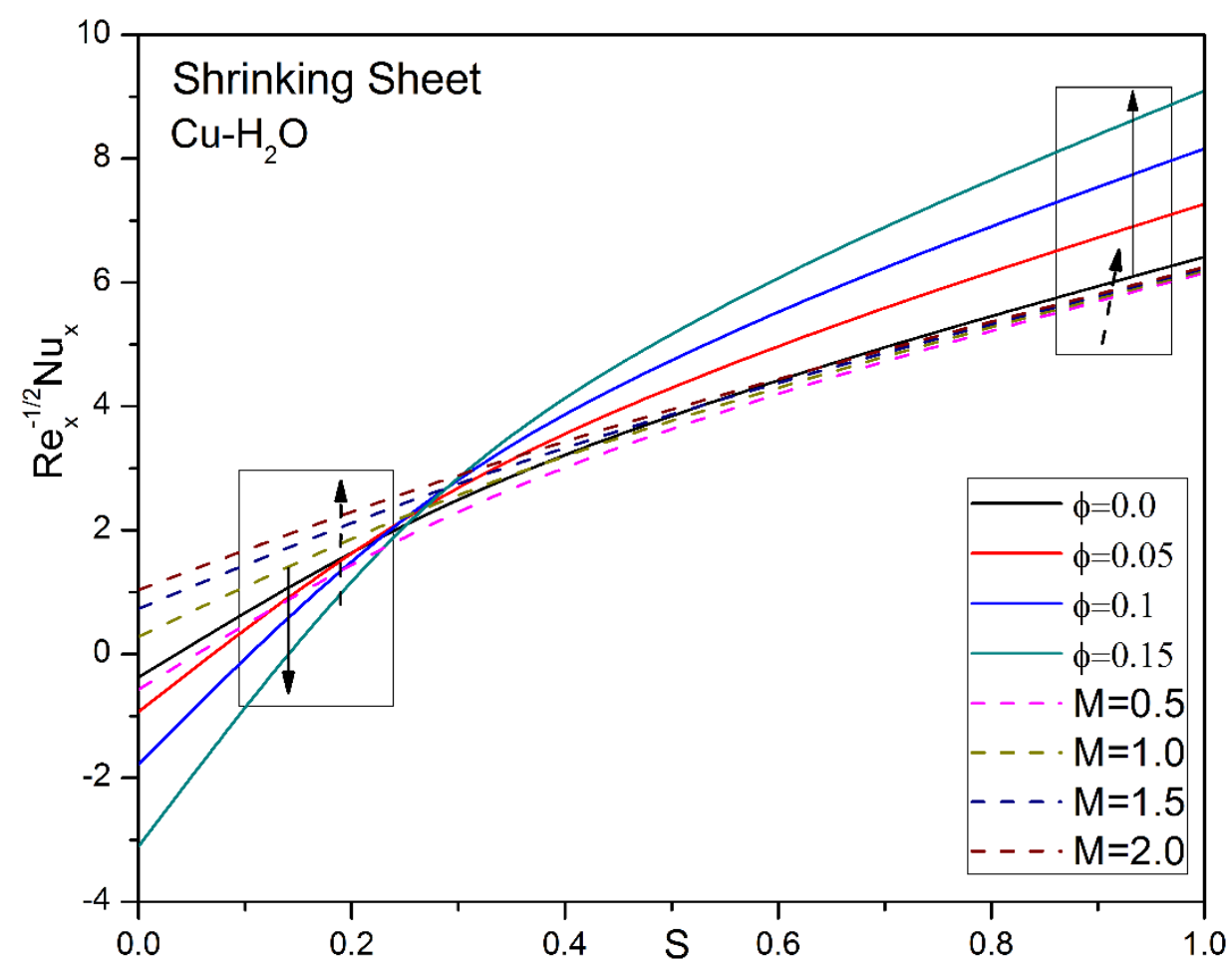

Fig. 34. Variation of the local Nusselt number with $\phi$ and $M$ for shrinking sheet. 


\section{Highlights}

- Inclined stretching/shrinking sheet magnetic nanofluid flow studied.

- Keller's box method employed for numerical solution.

- Heat source/sink, radiation and viscous dissipation effects examined.

- Stronger heat source increases thermal boundary layer thickness.

- Results are relevant to high-temperature magnetic nano-materials processing. 